Provided for non-commercial research and education use. Not for reproduction, distribution or commercial use.

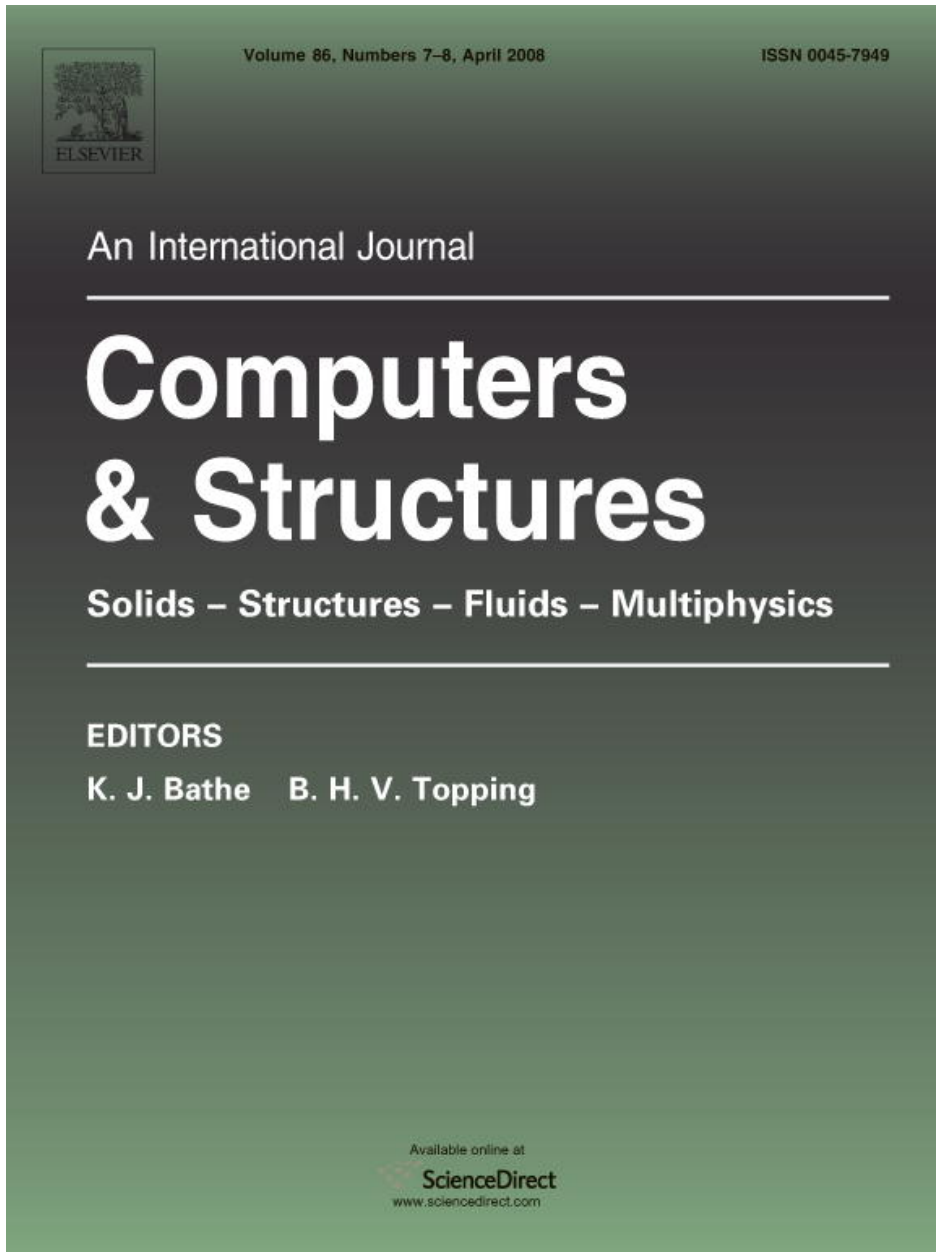

This article was published in an Elsevier journal. The attached copy

is furnished to the author for non-commercial research and education use, including for instruction at the author's institution, sharing with colleagues and providing to institution administration.

Other uses, including reproduction and distribution, or selling or licensing copies, or posting to personal, institutional or third party websites are prohibited.

In most cases authors are permitted to post their version of the article (e.g. in Word or Tex form) to their personal website or institutional repository. Authors requiring further information regarding Elsevier's archiving and manuscript policies are encouraged to visit: 


\title{
Plastic-damage seismic model for reinforced concrete frames
}

\author{
J. Faleiro, S. Oller *, A.H. Barbat \\ Escuela Técnica Superior de Ingenieros de Caminos, Canales y Puertos, Technical University of Catolonia, \\ Gran Capitán, s/n, Edificio C1, 08034 Barcelona, Spain
}

Received 21 February 2007; accepted 29 August 2007

Available online 22 October 2007

Abstract

A plastic-damage model for reinforced concrete frames is developed in this article, based on the classical plastic model and the continuum damage model. The plastic-damage constitutive law is implemented into a beam model for framed structures, in which these are described by elastic beams and columns with two inelastic hinges at their ends. A numerical procedure for predicting the member and global damage in framed structures using the matrix analysis is developed. Additionally, the article introduces a damage index useful in

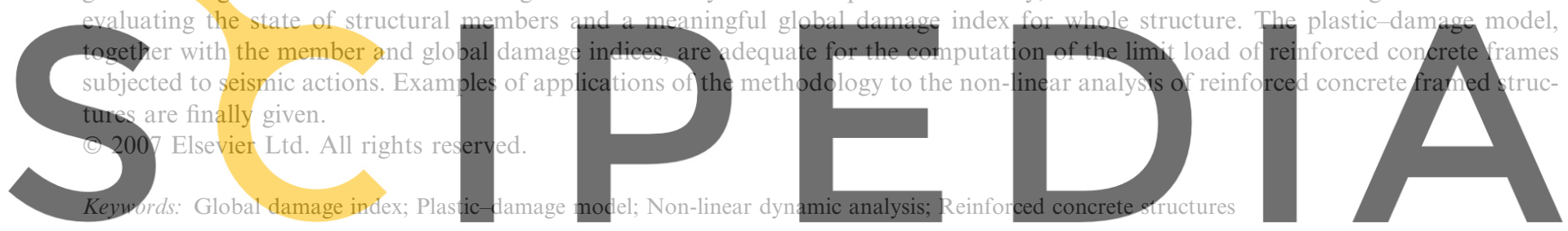

Register for free at https//www.scipedia.com to download the version without the watermark Contents

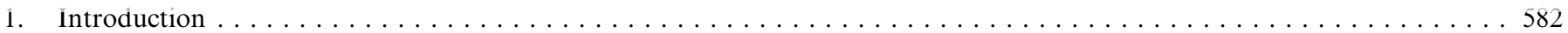

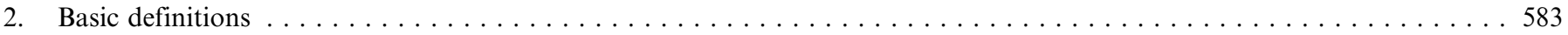

3. Concentrated plasticity approach for undamaged framed structures $\ldots \ldots \ldots \ldots \ldots \ldots$

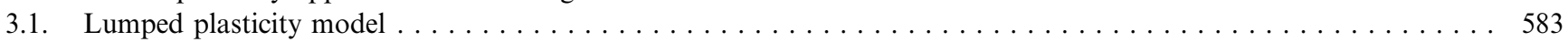

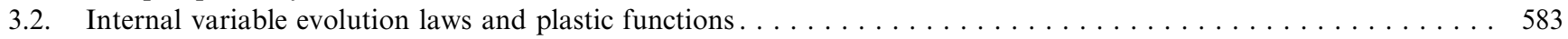

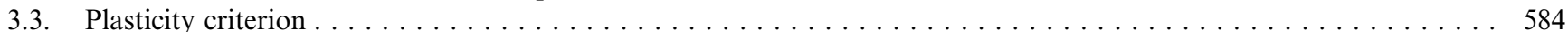

4. Continuous damage model for unplastified framed structures $\ldots \ldots \ldots \ldots \ldots \ldots$

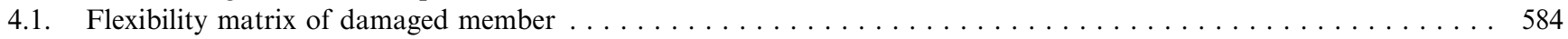

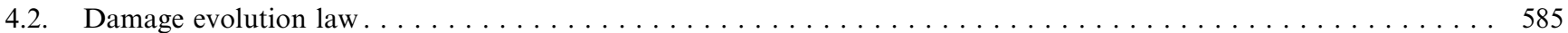

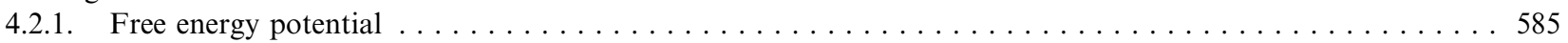

4.2.2. Energy norm for the undamaged structure and damage evolution $\ldots \ldots \ldots \ldots \ldots \ldots$

5. Plastic-damage model for reinforced concrete frames $\ldots \ldots \ldots \ldots \ldots \ldots \ldots \ldots$

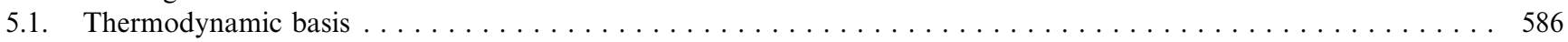

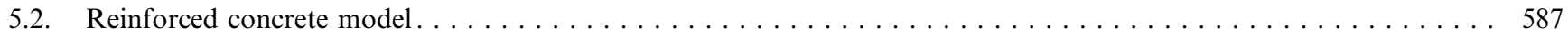

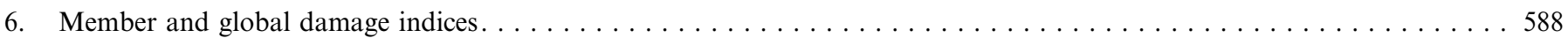

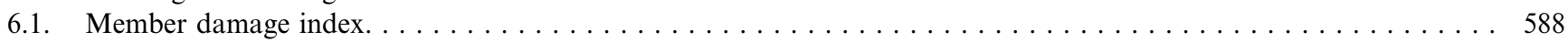

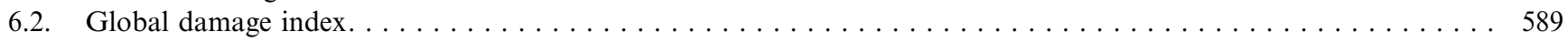

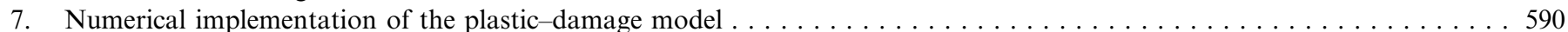

\footnotetext{
${ }^{*}$ Corresponding author. Tel.: +34 93 4016485; fax: +34 934011048.

E-mail address: oller@cimne.upc.edu (S. Oller).
} 
8. Numerical examples. . . . . . . . . . . . . . . . . . . . . . . . . . . . . 591

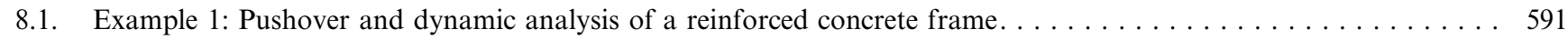

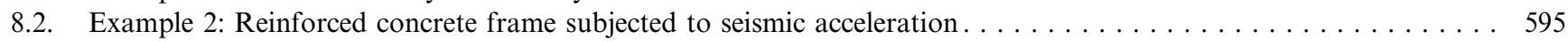

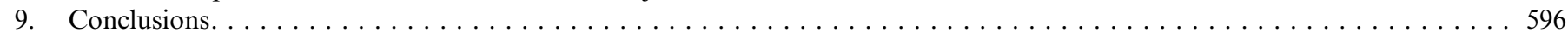

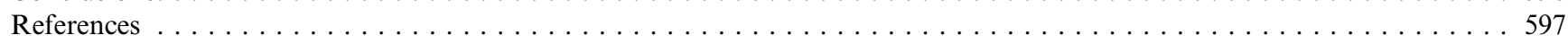

\section{Introduction}

When an urban area is affected by a strong ground motion, many buildings are damaged at different degrees and their safety is doubtful. It is essential to dispose of loss scenarios (or seismic risk scenarios) for that area, envisaged to guide decision making related to the seismic risk reduction and the emergency resnonse. In order to develon such scenarios in which the damaged state of the buildings and of the infrastructure plays a crucial role, the seismic damage of the structures has to be expressed by means of indices [1]. In many cases, these scenarios have as a starting point the evaluation of the damage-related phenomena in the structures of that area by using numerical simulation. Because a large scale damage evaluation is required in an urban area, it needs the use of more simplified structural

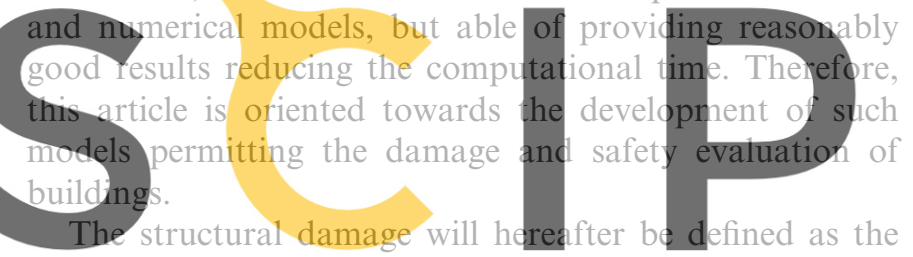
degree of degradation that allows conclusions about the Register for frue at htthstand further loadings. It will damage normalized to the failure level of the structure, so that a value equal to 1 will correspond to the complete structural failure. The damage evaluation of framed structures is a topic extensively studied in the last decade. In this article we contribute to this topic proposing a solution of the problem using a continuum mechanical model incorporated into the classical beam formulation, oriented towards improving the computational efficiency of the solution.

Different definitions of global damage indices have been given in the literature for complex structures, generally based on a weighted average of the indices corresponding to different structural members [2]. Other works define a damage index for structural members using a linear combination between ductility and an energy factor [3]. A global damage index which is formulated starting from potential energy considerations is developed in this paper for reinforced concrete structures, based on the concepts proposed by [4-6]. This index uses a local damage constitutive model, based on Kachanov's theory [7]. In this article the label "member damage" is applied only to damage indices describing the state of the members of the frames while the "global" damage index refers to the state of the whole structure. Both damages indices are independent of the chosen constitutive models for the structural material.
The behaviour of the reinforced concrete can be described by means of continuum constitutive equations rates. Reinforced concrete shows two different phases during the loading process: the cracking of the concrete and the yielding of the reinforcement. The concrete cracking phase can be described by means of Continuum Damage Mechanics, while the yielding of steel is described by means of the Plasticity Theory. Both effects, damage and plasticity, can be solved simultaneously by means of an uncoupled plastic-damage model which allows describing adequately the behaviour of the reinforced concrete elements of the framed structures. There are many models based on Kachanov's theory where plasticity and damage are coupled [8-11]. This approach has the advantage of allowing the development of independent constitutive equations which simulate materials where the plastic defor-
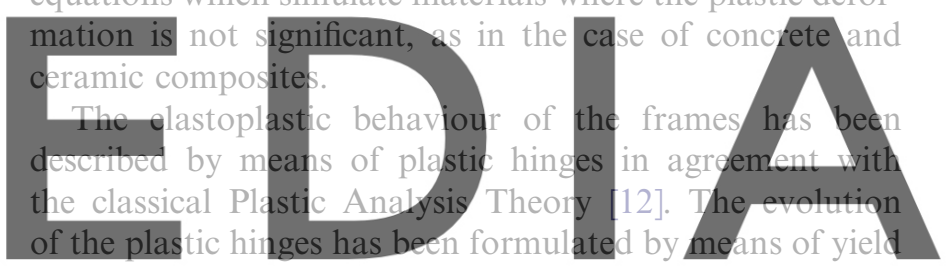

functions for both beams and columns [13]. Using the dumped plasticity model, Refs. [14 15] adapted the damage

damage is concentrated in plastic hinges, developing a concentrated damage model.

The objective of this paper is to develop an improved analytical model for predicting the plastic-damage response of multi-storey reinforced concrete frames, in accordance with the classic theories of Continuum Damage Mechanics and of classic Theories of Plasticity. Usually, such studies are based on finite element models of the structure [6] which give support to the structural analysis and to the implementation of the global damage indices. What distinguishes this work from others is the fact the complete plastic-damage constitutive model, as well as the global damage, are here implemented into a beam model of the framed structure, which is described by elastic beams and columns with two inelastic hinges at their ends. The damage in the hinges is obtained by means of the concentrated damage concepts; however, its evolution is based on the isotropic strain damage [8].

The paper is organized as follows: the theoretical bases of the plastic-damage model are introduced as a supporting theory of the global damage methodology. The matrix analysis implementation is then briefly outlined. Examples of application of the methodology to non-linear analysis of reinforce concrete structures are finally presented, includ- 
ing a three story and two bay reinforced concrete framed structure subjected to a sine function and a six story two bay reinforced concrete frame subjected to a seismic action.

\section{Basic definitions}

Let us consider a plane frame with $b$ elements connected into nodes. The generalized deformations $\boldsymbol{\Phi}_{b}$ of the beam $b$ can be defined as

$$
\boldsymbol{\Phi}_{b}^{\mathrm{T}}=\left\{\begin{array}{lll}
\phi_{i} & \phi_{j} & \delta
\end{array}\right\}
$$

where $\phi_{i}$ and $\phi_{j}$ indicate rotations of the member at the ends $i$ and $j$, respectively, and $\delta$ is its elongation. The generalized deformations $\boldsymbol{\Phi}_{b}$ can be expressed in terms of the global displacement $\mathbf{U}$ by

$\mathbb{D}_{b}(t)=\mathbb{B}_{b} \cdot \mathbb{U}(t)$

where $\mathbf{B}_{b}$ is the global displacement transformation matrix. The generalized stress vector of the frame element $b$ is defined as $[14,16]$

$\boldsymbol{M}_{b}^{\mathrm{T}}=\left\{\begin{array}{lll}m_{i} & m_{j} & n\end{array}\right.$

which contains the final forces of the member, where $m_{i}$ and $m_{j}$ are the moments at the ends of the member and $n$

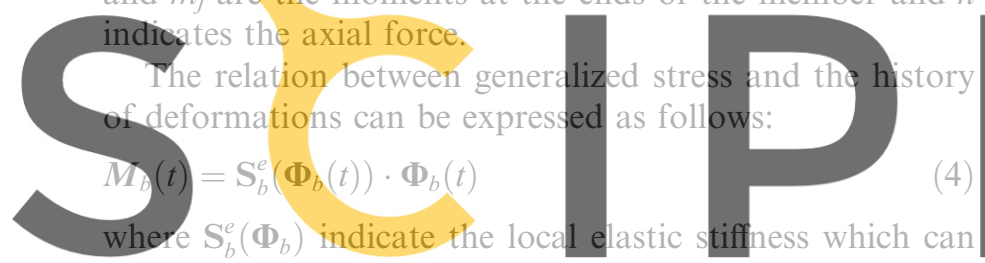

be defined according to the deformed configuration of the member. In the case of small strains, the elastic stiffness

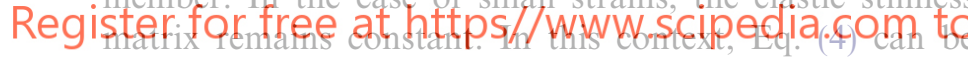
rewritten as

$\overline{\boldsymbol{M}}_{b}=\mathbf{S}_{b}^{e} \cdot \overline{\boldsymbol{\Phi}}_{b}$

The internal force is the sum of all generalized effective stress $M_{b}$

$\mathbf{F}_{\text {int }}(t)=\sum_{b=1}^{3 n \text {th }} \mathbf{B}_{b}^{\mathrm{T}} \cdot \boldsymbol{M}_{b}(t)$

while the vector inertial forces $\mathbf{F}_{i}(t)$ is obtained as

$\mathbf{F}_{i}(t)=\underbrace{\sum_{b=1}^{3 n t h}\left[\mathbf{m}_{g}\right]_{b}}_{\left[\mathbf{M}_{g}\right]} \cdot \ddot{\mathbf{U}}(t)$

where $\ddot{\mathbf{U}}(t)$ is the acceleration vector. The elemental mass matrix for element $b,\left[\mathbf{m}_{g}\right]_{b}$, can be consistent or concentrated if it has values different from zero only in the diagonal [17].

Using now the expressions of the inertial an internal forces, the equation of motion is formulated as

$\mathbf{M}_{g} \cdot \ddot{\mathbf{U}}(t)+\mathbf{F}_{\text {int }}(t)=\mathbf{F}_{\text {ext }}(t)$

where the $\mathbf{F}_{\text {ext }}(t)$ is the vector of dynamic load. Inserting Eqs. (5) into (8) and expanding the expression as a function of displacements:
$\mathbf{M}_{g} \cdot \ddot{\mathbf{U}}(t)+\underbrace{\left(\sum_{b=1}^{3 n t h} \mathbf{B}_{b}^{\mathbf{T}} \cdot \mathbf{S}_{b} \cdot \mathbf{B}_{b}\right) \cdot \mathbf{U}(t)}_{\mathbf{F}_{\text {int }}(t)}=\mathbf{F}_{\text {ext }}(t)$

where $\mathbf{K}^{e}=\sum \mathbf{B}_{b}^{\mathrm{T}} \cdot \mathbf{S}_{b}^{e} \cdot \mathbf{B}_{b}$ is the global stiffness matrix.

\section{Concentrated plasticity approach for undamaged framed structures}

For many reinforced concrete cross-sections, the spread of plasticity starting from the ends of the members along the length is not very significant and the deformation is concentrated at or near the ends cross-sections [13]. Therefore, we will assume that the plasticity is concentrated at the end cross-section. We also assume that the end crosssections plastify suddenly rather than gradually or fiberby-fiber, and that the material behaves in a perfectly elastic-plastic manner.

\subsection{Lumped plasticity model}

A constitutive equation can be obtained relating the generalized stress $M_{b}$ with the generalized deformations $\Phi_{b}$ by using the lumped dissipation model, considering plasticity, hardening or any other energy dissipation mech-

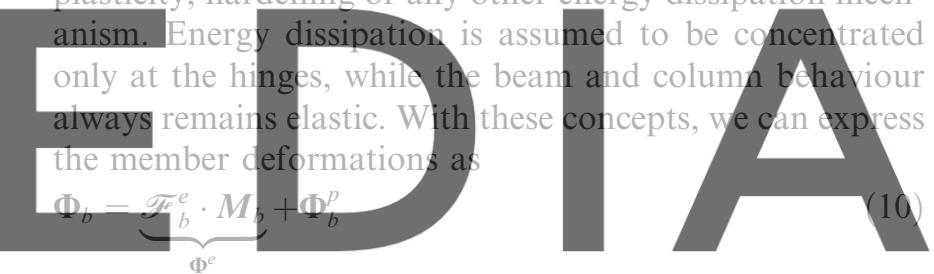

The term $\Phi^{e}=\mathscr{T}_{b}^{e} \cdot M_{b}$ corresponds to the beam-column dombload thetiversion ivithadtithe water, mank $\Phi_{b}^{p}$ is called plastic hinge deformation

$$
\left\{\overline{\boldsymbol{\Phi}}_{b}^{p}\right\}^{\mathrm{T}}=\left\{\begin{array}{lll}
\phi_{i}^{p} & \phi_{j}^{p} & \delta^{p}
\end{array}\right\}
$$

where $\phi_{i}^{p}$ and $\phi_{j}^{p}$ represent the plastic rotations of the member at the ends $i$ and $j$ respectively, and $\delta^{p}$ is its plastic elongation.

Using the generalized stress $\boldsymbol{M}_{b}$ from Eq. (10), we obtain [18]

$\boldsymbol{M}_{b}=\mathbf{S}_{b}^{e} \cdot\left(\boldsymbol{\Phi}_{b}-\boldsymbol{\Phi}_{b}^{p}\right)$

Eq. (12) assumes that plastic hinges appear when the load increases until the structure becomes unstable (or a mechanism) due to the development of various plastic hinges, fact identified by the algorithm through the singularity of the global stiffness matrix of the structure.

\subsection{Internal variable evolution laws and plastic functions}

For the internal variables defined in Eq. (11), for each hinged end $i$ and $j$ of the beam subjected to bending, the plastic deformation evolution laws are

$\dot{\phi}_{i}^{p}=\dot{\lambda}_{i}^{p} \frac{\partial f_{i}}{\partial m_{i}} ; \quad \dot{\phi}_{j}^{p}=\dot{\lambda}_{j}^{p} \frac{\partial f_{j}}{\partial m_{j}}$ 
while for the case of axial mechanism, the plastic deformation evolution laws is [14]

$\dot{\delta}^{p}=\dot{\lambda}_{i}^{p} \frac{\partial f_{i}}{\partial n}+\dot{\lambda}_{j}^{p} \frac{\partial f_{j}}{\partial n}$

In these equations $f_{i} \leqslant 0$ and $f_{j} \leqslant 0$ are the yield functions for the hinges $i$ and $j$, respectively. These functions depend on the generalized stress $M_{b}$ and also on the internal variables and the plastic multipliers $\dot{\lambda}_{i}^{p}$ and $\dot{\lambda}_{j}^{p}$. The plastic multipliers, according to the Kuhn-Tucker conditions, are

No plasticity $\begin{cases}\dot{\lambda}_{i}^{p}=0 & \text { if } f_{i}<0 \text { or } \dot{\lambda}_{i}^{p} f_{i}=0 \\ \dot{\lambda}_{j}^{p}=0 & \text { if } f_{j}<0 \text { or } \dot{\lambda}_{j}^{p} f_{j}=0\end{cases}$

Plasticity state $\begin{cases}\dot{\lambda}_{i}^{p}>0 & \text { if } f_{i}=0 \text { and } \dot{\lambda}_{i}^{p} f_{i}=0 \\ \dot{\lambda}_{j}^{p}>0 & \text { if } f_{j}=0 \text { and } \dot{\lambda}_{j}^{p} f_{j}=0\end{cases}$

In order to have the plastic multiplier strictly positive, we will consider that the plastic deformation is 'active'; otherwise it will be called 'passive'. The solution of Eq. (15) requires the use of the so-called "return-algorithms", as proposed by [16]

\subsection{Plasticity criterion}

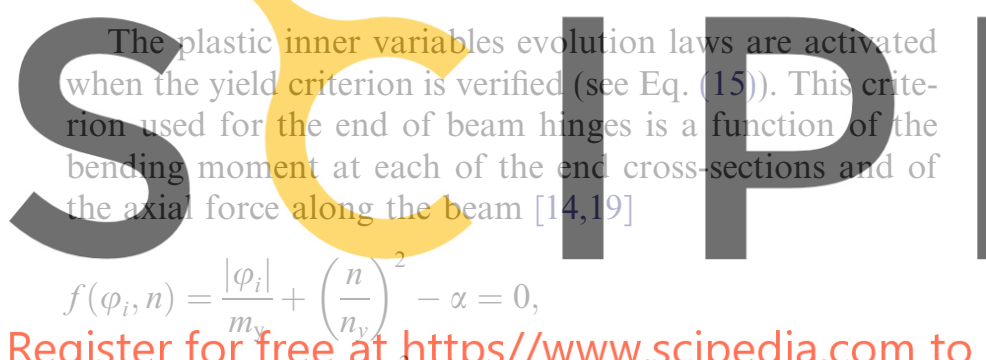

Register for free ät https//www.scipedia.com to $f\left(\varphi_{j}, n\right)=\frac{\left|\varphi_{j}\right|}{m_{\mathrm{y}}}+\left(\frac{n}{n_{y}}\right)^{2}-\alpha=0$

$\varphi_{i}=m_{i}-q_{i}, \quad \varphi_{j}=m_{j}-q_{j}$

where $m_{\mathrm{y}}$ is the yield moment or plastic moment, $n_{y}$ is the yield axial force, and the parameters $q_{i}$ and $q_{j}$ are called the back stresses and can be defined as [20]

$\mathrm{d} q_{i}=H \mathrm{~d} \phi_{i}^{P}, \quad \mathrm{~d} q_{j}=H \mathrm{~d} \phi_{j}^{P}$

where $H$ is the kinematics hardening modulus which is a propriety of the material; the parameter $\alpha$ is an additional
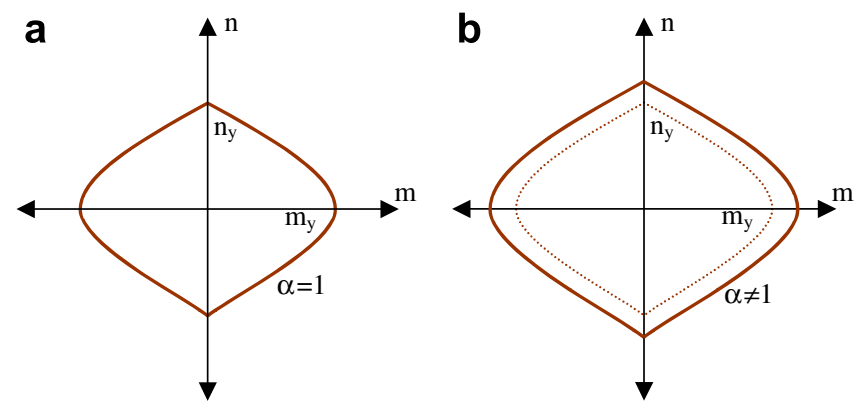

Fig. 1. Yield Surface in $m-n$ space: (a) without hardening effect and (b) with hardening. hardening function of the material whose effect can be seen in Fig. 1.

Despite the fact that the yield surface is the same for the hinges $i$ and $j$, the plastic multipliers are independent of each other. Other yield functions can be formulated to describe the complete yielding of the cross-section, the residual stress effects, or the behaviour of different materials, as proposed in Ref. [13].

\section{Continuous damage model for unplastified framed structures}

Some basic concepts of continuum mechanics, necessary for the subsequent development of the concentrated damage concepts, are reviewed herein [8]. Here we applied the damage effect on the properties of the elastic material while its influence in the plasticity parameters has been neglected. Physically, the degradation of the material properties is the result of the initiation, growth, and coalescence of microcracks or microvoids. Within the context of continuum mechanics, one may model this process by introducing an internal damage variable that can be a scalar or a tensorial quantity. Let us consider $\mathbf{A}$, a fourth-order tensor, which characterizes the state of damage and transforms the effective stress tensor, $\overline{\boldsymbol{\sigma}}$, into the homogen zed one, $\sigma$, or vice
versa
$\sigma=A: \overline{\boldsymbol{\sigma}}$
For the isotrop ic damage case, the mechanidal behaviour
of microcracks or microvoids is independent of their orientation and depends only on a scalar variable $d$. For this reason, $\mathbf{A}$ will simply reduce. to $\mathbf{A}=(1-d) \mathbf{I}$, where $\mathbf{I}$ is a rank downdead the versson withouththe watermark $\sigma=(1-d) \bar{\sigma}$

where $d$ is the scalar damage internal variable, $\sigma$ the Cauchy stress tensor and $\bar{\sigma}$ is the effective stress tensor, both at time $t$. Here, $d \in(0,1]$ is a given constant. The coefficient $1-d$ dividing the stress tensor in Eq. (20) is a reduction factor associated with the amount of damage in the material, initially introduced by Kachanov. The value $d=0$ corresponds to the undamaged state, whereas a value $d=1$ corresponds to a complete damaged state defining a local rupture. Another possible interpretation is that, physically, the damage parameter $d$ is the ratio of the damage crosssection area to the total cross-section area.

\subsection{Flexibility matrix of damaged member}

Consider that the concentrated damage of the frame element $b$ is defined as [21,22].

$$
\left\{\mathbf{D}^{b}\right\}^{\mathrm{T}}=\left\{\begin{array}{lll}
d_{i} & d_{j} & d_{\delta}
\end{array}\right\}
$$

where $d_{i}$ and $d_{j}$ are a measure of the bending concentrated damage at the ends $i$ and $j$ of the beam member, respectively, and $d_{\delta}$ indicates the measure of the axial damage of the member. These variables can take values between 
zero (no damage) and one (completely damaged). This hypothesis of the decomposition into axial and flexural damage variables allows avoiding the crashing effects in the beam model and maintaining the structural stability when the bending damage reaches the maximum value in the concrete. In the same way as in the case of the plasticity, all the bending concentrated damage parameters are concentrated at the nodes. Supposing the existence of a flexibility bending matrix of a damaged member $\left[\mathscr{F}_{b}^{d}\right]_{\text {bend }}$ we have [16]

$\left[\mathbf{\Phi}_{b}\right]_{\text {bend }}=\left[\mathscr{\mathscr { F }}_{b}^{d}\right]_{\text {bend }} \cdot\left[M_{b}\right]_{\text {bend }} \Rightarrow$

$\left\{\begin{array}{l}\phi_{i} \\ \phi_{j}\end{array}\right\}_{\text {bend }}=\left[\begin{array}{ll}f_{i i} & f_{i j} \\ f_{j i} & f_{j j}\end{array}\right]_{\text {bend }}\left\{\begin{array}{l}m_{i} \\ m_{j}\end{array}\right\}_{\text {bend }}$

$\left[\mathscr{F}_{b}^{d}\right]_{\text {bend }}=\frac{L}{6 E I}\left[\begin{array}{cc}\frac{2}{\left(1-d_{i}\right)} & -1 \\ -1 & \frac{2}{\left(1-d_{j}\right)}\end{array}\right]_{b}$

The inverse of $\left[\mathscr{\mathscr { J }}_{b}^{d}\right]_{\text {bend }}$ is the stiffness bending matrix of a damaged member $\left[\mathbf{S}_{b}^{d}\right]_{\text {bend }}=\left[\mathscr{\mathscr { F }}_{b}^{d}\right]_{\text {bend }}^{-1}$. If we also include the influence of axial mechanism in an uncoupled form, and redefine the stiffness matrix as a function of concentrated damage vector $\mathbb{D}^{b}$ for an element $b$, in small displacements

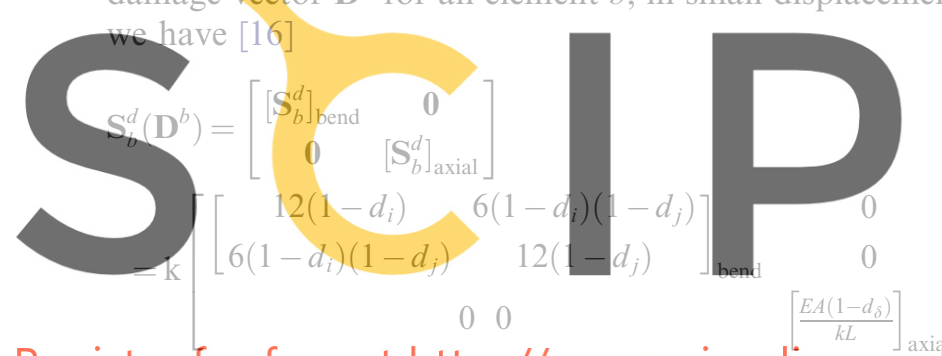

Register for free at https//www.scipedia.com( 29

where $k=\frac{1}{4-\left(1-d_{i}\right)\left(1-d_{j}\right)} \frac{E I}{L}$. In the particular case when $\mathbf{D}^{b}$ trends to zero, $\mathbf{S}_{b}^{d}$ reduces to the standard stiffness elastic $\operatorname{matrix} \mathbf{S}_{b}^{d}\left(\mathbf{D}^{b}=\mathbf{0}\right) \Rightarrow \mathbf{S}_{b}^{e}$.

\subsection{Damage evolution law}

In order to apply the Continuum Damage Mechanics concepts to the framed structures analysis, it is necessary to express the damage variable evolution as a function of the deformations at the hinges $i$ and $j$, as well as of the deformation due to the elongation $\delta$. In addition, another necessary condition is that the evolutions of the damage variable should be independent of each other.

\subsubsection{Free energy potential}

Defining the free energy $\Psi_{\varepsilon}=1 / 2 \varepsilon: \mathbf{C}: \boldsymbol{\varepsilon}$ [23], where $\mathbf{C}$ is the constitutive tensor, $\boldsymbol{\varepsilon}$ is the total strain in each point of the solid, and redefining it for a frame element $b$ as a function of generalized strains $\boldsymbol{\Phi}_{b}$ and the stiffness matrix $\mathbf{S}_{b}$, we obtain the free energy potential as [18]

$\Psi\left(\boldsymbol{\Phi}_{b}\right)=\Psi^{0}=\frac{1}{2} \boldsymbol{\Phi}_{b} \cdot \mathbf{S}_{b} \cdot \boldsymbol{\Phi}_{b}$
By rewriting (25) in terms of the rotations $\phi_{i}$ and $\phi_{j}$ at the ends of the element, as well as of the elongation $\delta$, we obtain

$$
\begin{aligned}
\Psi^{0}= & \frac{1}{2}\left(4 \frac{E I}{L} \phi_{i}+2 \frac{E I}{L} \phi_{j}\right) \phi_{i} \\
& +\frac{1}{2}\left(4 \frac{E I}{L} \phi_{j}+2 \frac{E I}{L} \phi_{i}\right) \phi_{j}+\frac{1}{2} \frac{E A}{L} \delta^{2}
\end{aligned}
$$

In Eq. (26) we observe that the free energy potential is the sum of the energies due to the rotations at the nodes $i$ and $j$ and to the elongation $\delta$, in such a way that the free energy potential can be redefined as $\Psi^{0}=\Psi_{i}^{0}+\Psi_{j}^{0}+\Psi_{\delta}^{0}$ where

$$
\begin{aligned}
& \Psi_{i}^{0}=\frac{1}{2}\left(4 \frac{E I}{L} \phi_{i}+2 \frac{E I}{L} \phi_{j}\right) \phi_{i}, \\
& \Psi_{j}^{0}=\frac{1}{2}\left(4 \frac{E I}{L} \phi_{j}+2 \frac{E I}{L} \phi_{i}\right) \phi_{j} \text { and } \Psi_{\delta}^{0}=\frac{1}{2} \frac{E A}{L} \delta^{2}
\end{aligned}
$$

Introducing now $m_{i}=4 \frac{E I}{I} \phi_{i}+2 \frac{E I}{I} \phi_{j}, m_{j}=4 \frac{E I}{I} \phi_{j}+2 \frac{E I}{I} \phi_{i}$ and $n=\frac{E A}{L} \delta$, we can express $\Psi_{i}^{0}, \Psi_{j}^{0}$, and $\Psi_{\delta}^{0}$ in terms of the moments at the ends of the beam $m_{i}$ and $m_{j}$ and the axial force $n$ as

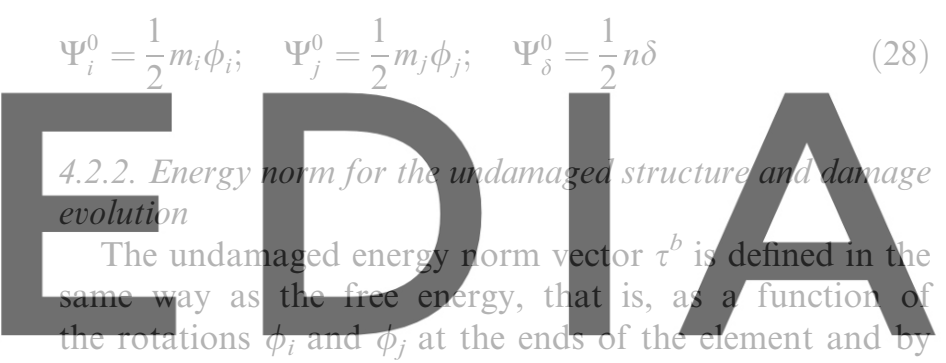

the elongation $\delta[22]$

download the version without the watermark

$$
=\left\{\begin{array}{l}
\tau_{i}^{b}=\sqrt{2 \Psi_{i}^{0}}=\sqrt{\left(4 \frac{E I}{L} \phi_{i}+2 \frac{E I}{L} \phi_{j}\right) \phi_{i}} \\
\tau_{j}^{b}=\sqrt{2 \Psi_{j}^{0}}=\sqrt{\left(4 \frac{E I}{L} \phi_{j}+2 \frac{E I}{L} \phi_{i}\right) \phi_{j}} ; \quad \forall k \in(i, j, \delta) \\
\tau_{\delta}^{b}=\sqrt{2 \Psi_{\delta}^{0}}=\sqrt{\frac{E A}{L} \delta^{2}}
\end{array}\right.
$$

We characterize the damage state of the frame elements by means of three different and independent damage criteria: two of them are applied in the hinges at each end of the beam ( $i$ and $j$ ) and the third one is used for the axial damage control along the beam. This independent axial damage criterion allows the control of the axial stiffness of the reinforced concrete beam when the bending damage is reached in the concrete but the steel has only elastic/plastic behaviour

$$
g_{k}\left(\tau_{k}^{b}, r_{k}^{b}\right)_{t}=\left\{\begin{array}{l}
g_{i}\left(\tau_{i}^{b}, r_{i}^{b}\right)_{t}=\left(\tau_{i}^{b}\right)_{t}-\left(r_{i}^{b}\right)_{t} \leqslant 0 \\
g_{j}\left(\tau_{j}^{b}, r_{j}^{b}\right)_{t}=\left(\tau_{j}^{b}\right)_{t}-\left(r_{j}^{b}\right)_{t} \leqslant 0 ; \quad \forall k \in(i, j, \delta) \\
g_{\delta}\left(\tau_{\delta}^{b}, r_{\delta}^{b}\right)_{t}=\left(\tau_{\delta}^{b}\right)_{t}-\left(r_{\delta}^{b}\right)_{t} \leqslant 0
\end{array}\right.
$$


Here, the subscript $t$ refers to the value at current time $t \in \mathbb{R}_{+}, r_{i}^{b}, r_{j}^{b}$ and $r_{\delta}^{b}$ are the damage thresholds at the current time for the rotations $\phi_{i}$ and $\phi_{j}$ and for the elongation $\delta$, respectively. We consider a vector $r_{0}$, for $t=0$, which denotes the initial damage threshold before applying any load, defined as

$$
\begin{aligned}
\left(r_{k}^{b}\right)_{0}= & \sqrt{\left(M_{b}\right)_{\mathrm{y}} \cdot \mathbf{S}_{b}^{-1} \cdot\left(M_{b}\right)_{\mathrm{y}}}=\left\{\begin{array}{l}
\left(r_{i}^{b}\right)_{0} \\
\left(r_{j}^{b}\right)_{0} \\
\left(r_{\delta}^{b}\right)_{0}
\end{array}\right\} \\
& \Rightarrow\left\{\begin{array}{l}
\left(r_{i}^{b}\right)_{0}=\left(r_{j}^{b}\right)_{0}=\sqrt{\frac{L}{3 E I} m_{\mathrm{y}}^{2}} \\
\left(r_{\delta}^{b}\right)_{0}=\sqrt{\frac{L}{E A} n_{y}^{2}}
\end{array} \quad \forall k \in(i, j, \delta)\right.
\end{aligned}
$$

where $m_{\mathrm{y}}$ and $n_{\mathrm{y}}$ are the limit values of the bending moment and axial force, respectively. The vector $r_{0}$ can be considered as a property characteristic of the element, in such a way that we must have $\left(r_{k}^{b}\right)_{t} \geqslant\left(r_{k}^{b}\right)_{0}, \forall k \in(i, j, \delta)$. Eq. (30) states that damage in the element is initiated when the energy norm vector $\tau^{b}$ exceeds the initial damage threshold $r_{0}$. For the isotropic case, we define the evolution of the damage variables by

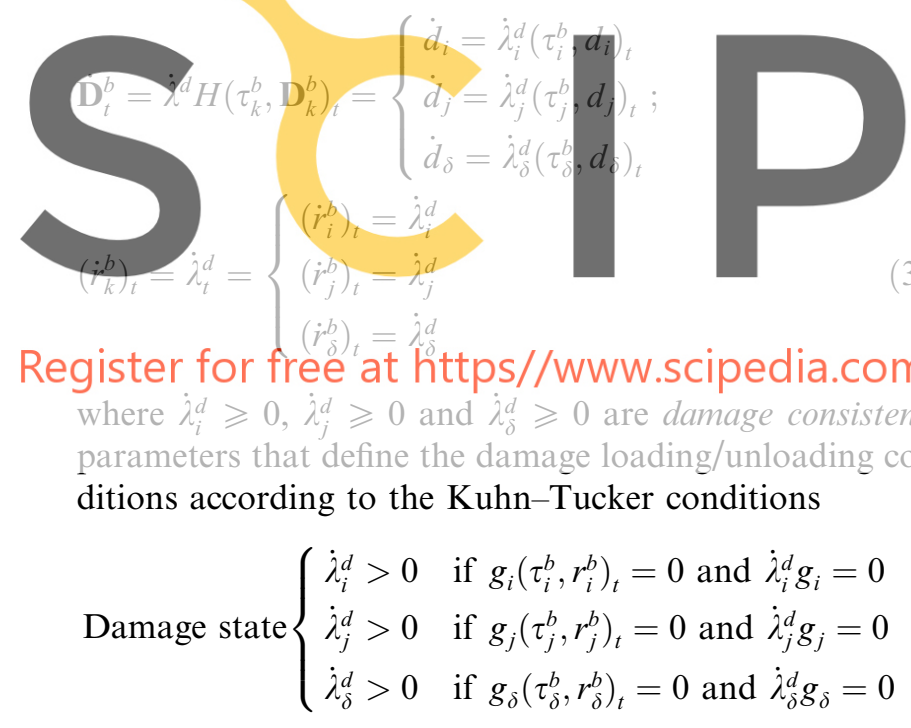

(32)

$$
\begin{aligned}
\left(r_{k}^{b}\right)_{t} & =\max \left\{\left(r_{k}^{b}\right)_{t}, \max _{s \in(0, t)}\left(\tau_{k}^{b}\right)_{s}\right\} \\
& =\left\{\begin{array}{l}
\max \left\{\left(r_{i}^{b}\right)_{0}, \max _{s \in(0, t)}\left(\tau_{i}^{b}\right)_{s}\right\} \\
\max \left\{\left(r_{j}^{b}\right)_{0}, \max _{s \in(0, t)}\left(\tau_{j}^{b}\right)_{s}\right\} \\
\max \left\{\left(r_{\delta}^{b}\right)_{0}, \max _{s \in(0, t)}\left(\tau_{\delta}^{b}\right)_{s}\right\}
\end{array}\right.
\end{aligned}
$$

If we now consider that $H\left(\left(\tau_{k}^{b}\right)_{t}, \mathbf{D}_{t}^{b}\right)$ in condition (32) is independent of the vector $\mathbf{D}_{t}^{b}$ and we also assume the existence of a monotonic function $G$, such that $H\left(\tau_{k}^{b}\right)_{t}=$ $\partial G\left(\tau_{k}^{b}\right)_{t} / \partial\left(\tau_{k}^{b}\right)_{t}$, the damage criterion defined in (30) can be rewritten as a function of $G$, i.e. at hinge $\mathrm{kg}_{k}\left(\tau_{k}^{b}, r_{k}^{b}\right)_{t}=$ $G\left(\tau_{k}^{b}\right)_{t}-G\left(r_{k}^{b}\right)_{t} \leqslant 0$. In this way, the flow rule (32) and loading/unloading conditions (33) become
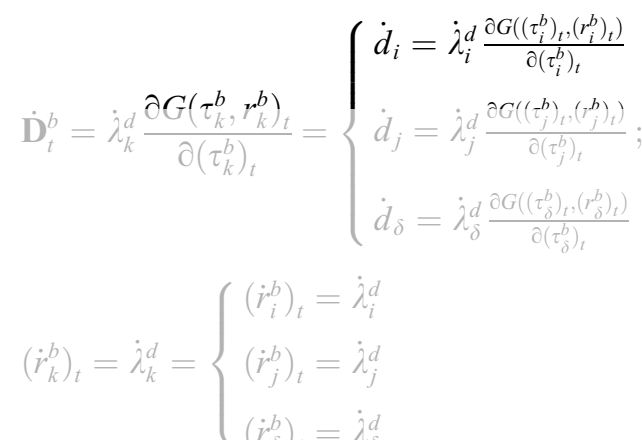

(36)

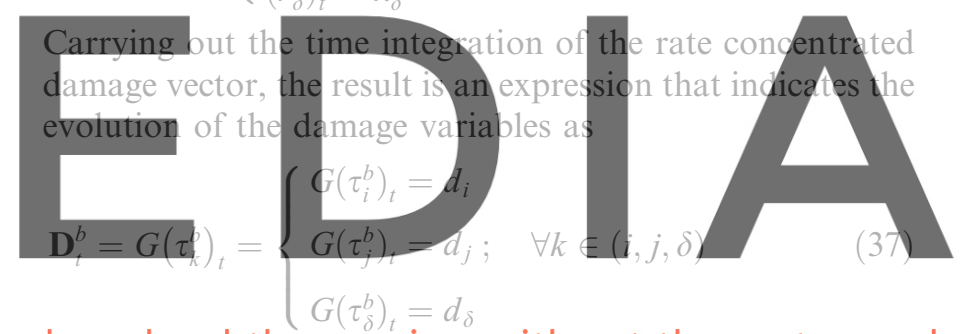

\section{down pad the version without the watermark} age variable must be monotonic in the range $0 \leqslant G(\cdot) \leqslant 1$ and can be defined according to the type of analysis. In our work, the expression of the exponential softening proposed by [24] was used

$G\left(\tau_{k}^{b}\right)_{t}=1-\frac{\left(\tau_{k}^{b}\right)_{t}}{\left(r_{k}^{b}\right)_{0}} \mathrm{e}^{A\left(1-\frac{\left(r_{k}^{b}\right)_{0}}{\left(\tau_{k}^{b}\right)_{t}}\right)} ; \quad \forall k \in(i, j, \delta)$

where the energy norm vector is ranged $0 \leqslant\left(\tau_{k}^{b}\right)_{t} \leqslant\left(r_{k}^{b}\right)_{0}$ and $A=1 /\left[\frac{g_{\mathrm{f}} E_{0}}{\left(r_{k}^{b}\right)_{0}^{2}}-\frac{1}{2}\right]$. The parameter $g_{\mathrm{f}}$ is the fracture energy of the material defined by the regularization $g_{\mathrm{f}}=G_{\mathrm{f}} / l_{\mathrm{c}}$, where $G_{\mathrm{f}}$ is the fracture energy and $l_{\mathrm{c}}$ is the characteristic length of the fractured member [24]. Alternatively, $l_{\mathrm{c}}=\sqrt{A}$, where $A$ is the element cross-section area [25]. More and deep information about of the damage scalar function $G(\cdot)$ can be seen in references $[4,24,26]$.

\section{Plastic-damage model for reinforced concrete frames}

\subsection{Thermodynamic basis}

In the concrete of the structural elements, the effect of damage modifies the constitutive plastic equation for small
Finally, $\left(r_{k}^{b}\right)_{t}$ can be calculated by means of the expression $\left(r_{k}^{b}\right)_{t}=\max \left\{\left(r_{k}^{b}\right)_{0}, \max _{s \in(0, t)}\left(\tau_{k}^{b}\right)_{s}\right\}$. By applying it to all parameters, we obtain 
deformations by the degradation of the stiffness. A new constitutive equation is formulated without time variation of temperature for thermodynamically stable problems, using the following mathematical formulation for the free energy constituted by elastic and plastic terms $[18,24]$

$\Psi_{b}\left(\boldsymbol{\Phi}_{b}^{e}, \mathbf{D}^{b}, q^{p}\right)=\Psi_{b}^{e}\left(\boldsymbol{\Phi}_{b}^{e}, \mathbf{D}^{b}\right)+\Psi_{b}^{p}\left(q^{p}\right)$

where $\Psi^{p}$ is a plastic potential function and $\Psi^{e}\left(\boldsymbol{\Phi}_{b}^{e}, \mathbf{D}^{b}\right)$ is the initial elastic stored energy. Additionally, $q^{p}$ indicate a suitable set of plastic internal variables and the elastic deformations $\boldsymbol{\Phi}_{b}^{e}$ is the free variable of the process.

For this particular stable thermal beam problem, the reduced form of Clausius-Duhem dissipation inequality takes the form

$\dot{\Xi}=M_{b} \cdot \dot{\Phi}_{b}-\dot{\mathbf{\Psi}}_{b} \geqslant 0$

This inequality is valid for any loading-unloading stage. Taking the time derivative of Eq. (39) and substituting into (40), the following equation is obtained for dissipation:

$\dot{\boldsymbol{\Xi}}=\left[\boldsymbol{M}_{b}-\frac{\partial \Psi_{b}}{\partial \Phi_{b}^{e}}\right] \cdot \dot{\boldsymbol{\Phi}}_{b}+\frac{\partial \Psi_{b}}{\partial \Phi_{b}^{e}} \cdot \dot{\boldsymbol{\Phi}}^{p}-\frac{\partial \Psi_{b}}{\partial \mathbf{D}^{b}} \cdot \dot{\mathbf{D}}^{b}-\frac{\partial \Psi_{b}}{\partial q^{p}} \cdot \dot{q}^{p} \geqslant 0$

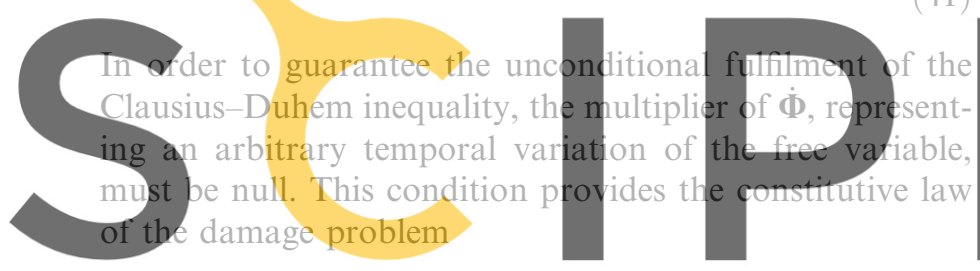

$\left.M-\frac{\partial \Psi_{b}}{M}\right]=0 \quad \forall \dot{\Phi}, \quad(42)$

Register fôp free at https//www.scipedia.com to

from where the final generalized stress of a member $b$ can be defined as

$\boldsymbol{M}_{b}=\frac{\partial \Psi_{b}}{\partial \boldsymbol{\Phi}_{b}^{e}}$

Once imposed the condition $\boldsymbol{\Phi}_{b}^{e}=\boldsymbol{\Phi}_{b}-\boldsymbol{\Phi}_{b}^{p}$, the free energy for an elastic-plastic frame element with stiffness degradation can be written for small deformations as

$\Psi_{b}\left(\boldsymbol{\Phi}_{b}^{e}, \mathbf{D}^{b}, q^{p}\right)=\frac{1}{2}\left(\boldsymbol{\Phi}_{b}-\boldsymbol{\Phi}_{b}^{p}\right) \cdot\left[\mathbf{S}_{b}^{d}\left(\mathbf{D}^{b}\right)\right] \cdot\left(\boldsymbol{\Phi}_{b}-\boldsymbol{\Phi}_{b}^{p}\right)+\Psi_{b}^{p}\left(q^{p}\right)$

where the stiffness matrix of the damaged member $\mathbf{S}_{b}^{d}\left(\mathbf{D}_{b}\right)$ is the same matrix defined in (24). By replacing this last equation into (43), one arrives at the expression for plastic-damage analysis $[14,15,22]$

$$
\boldsymbol{M}_{b}=\mathbf{S}_{b}^{d}\left(\mathbf{D}^{b}\right) \cdot\left(\boldsymbol{\Phi}_{b}-\boldsymbol{\Phi}_{b}^{p}\right)
$$

This constitutive equation contains the internal variables of plasticity and damage. In this expression, the following hypotheses are also assumed: The change of the elastic properties of the material is produced only by the damage phenomenon and the plasticity only produces incompatible strains.

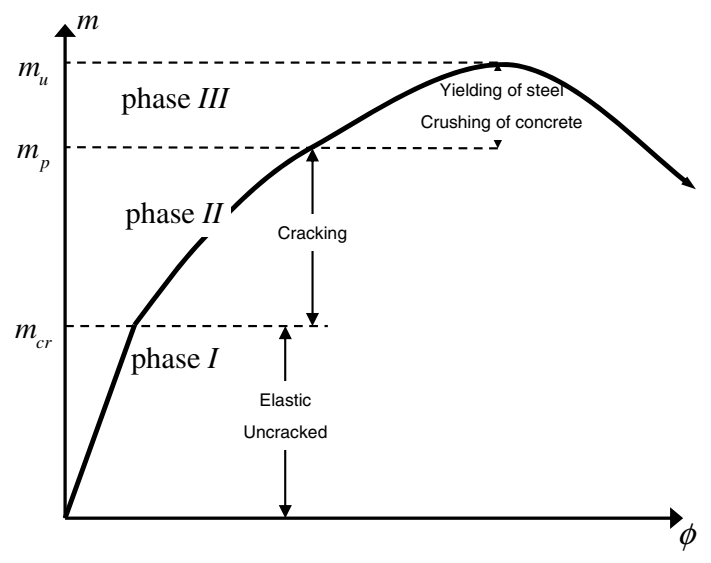

Fig. 2. Typical moment-deformation of a reinforced concrete beam: phase I and II correspond to the serviceability limit state; phase III defines the ultimate state.

\subsection{Reinforced concrete model}

The developments performed so far are appropriate for beams made of homogeneous materials. Now we introduce an approach which allows considering steel bars in this formulation. It is well known from experimental observations

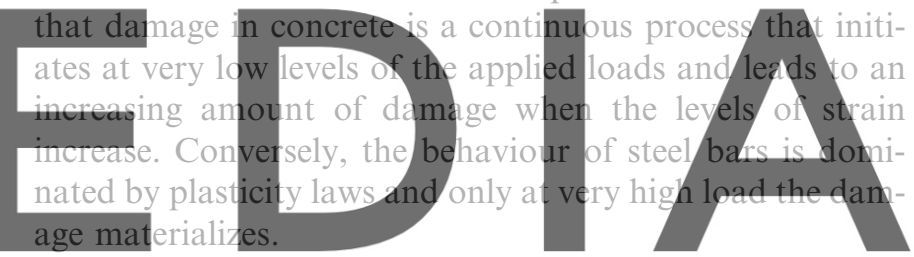

As proposed in Ref. [27], this highly non-linear behaviour fan be roughly split into three interyals: the uncracked

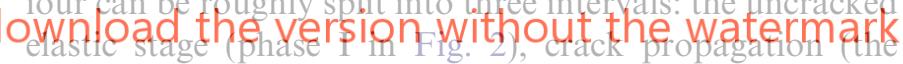

stress is within the elastic range, phase II in Fig. 2) and plastic stage (the beam reaches its ultimate strength, phase III in Fig. 2). The non-linear response is caused by the two major material effects: (1) cracking of the concrete and plasticity of the reinforcement and (2) compression of concrete. Thus, for reinforced concrete structures, plasticity is physically associated to the flow of the reinforcement, while damage indicates the cracking and rupture of the concrete.

In design, it is often assumed that concrete fails in compression when it reaches a compressive strain of $\varepsilon_{\mathrm{c}}=0.003$. Compressive failure occurs by occurrence of cracks parallel to the loading direction and is referred to as "splitting failure" [27]. The steel is assumed to have a linear stress-strain relation until the yield stress, $f_{\mathrm{y}}$, is reached. Beyond this value, it is assumed that the stress in the steel remains constant while strain increases, without hardening. The steel tensile strain at the beginning of yielding is $\varepsilon_{\mathrm{y}}$.

The cohesive (crack-bridging) stresses of the tensile cracks are significant only near the neutral axis, where they have a very little contribution to the plastic moment $m_{\mathrm{p}}$ or the nominal bending moment according to the notation of the American Concrete Institute [27]. As a rule based on experiments, the compression stress-strain distribution 


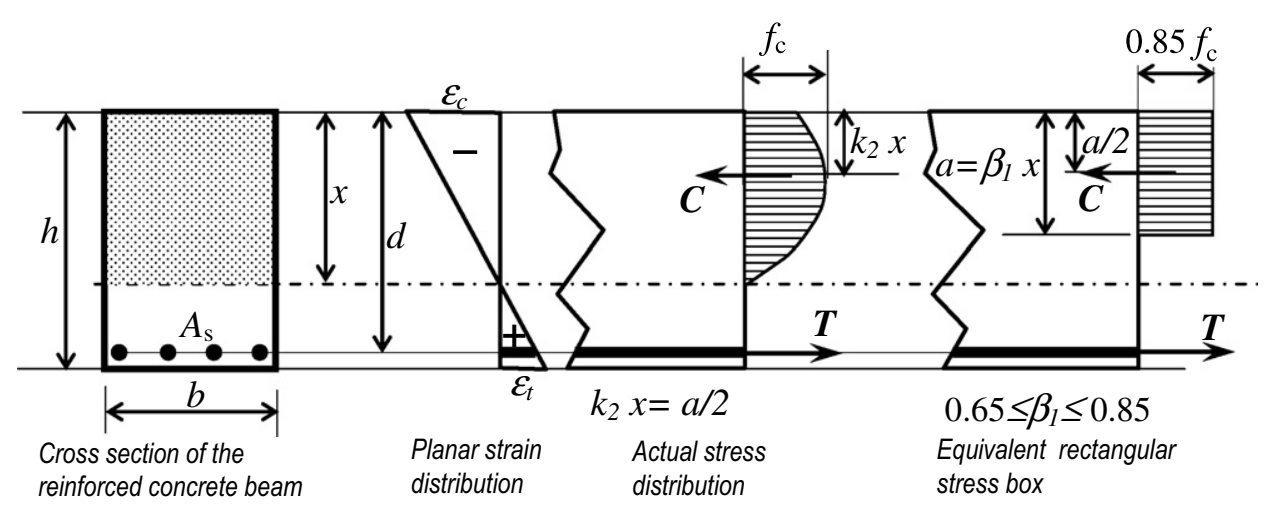

Fig. 3. Singly reinforced rectangular beam: cross-section and distributions of strains and stresses.

may be replaced by an equivalent rectangular stress block having an uniform stress magnitude of $0.85 f_{\mathrm{c}}$ and a depth $a$ that is less than the distance $x$ from the compressive face to the neutral axis $f_{\mathrm{c}}$ (see Fig. 3 ) is the standard compression strength obtained by rupture test performed on concrete samples.

Consider first a single reinforced rectangular cross-section of width $b$ and depth $d$ measured from the compression face to the centroid of the steal bars, as shown in Fig. 3. The equilibrium of the hor zontal forces requires
that $\left.0.85 f_{\mathrm{c}}\right) b \quad a=A_{s} f_{\mathrm{y}}=T$, where $T$ is the tensily steel
resultant $f_{\mathrm{y}}$ is the uniaxial yield strength of the bays and
$A_{s}$ is the combined cross-section area of all tensile steal
bars. Thus, according to [27]

$a=\frac{s f^{2}}{0.85 f_{\mathrm{c}} b}$

(46)

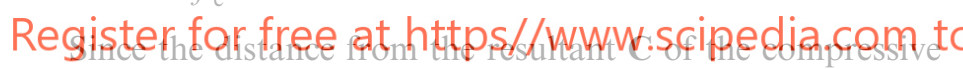

stresses in concrete to the tensile resultant $T$ is $d-\frac{1}{2} a$, the plastic moment is

$m^{p}=A_{s} f_{\mathrm{y}}\left(d-\frac{1}{2} a\right)=A_{s} f_{\mathrm{y}}\left(d-\frac{1}{2} \frac{A_{s} f_{\mathrm{y}}}{0.85 f_{\mathrm{c}} b}\right)$

Eq. (47) is valid only if the tensile steel yields before the compressed concrete crushes. For those cases where the longitudinal reinforcing steel bars are placed near the compressed face of the beams, Eq. (47) can be rewritten as [27]

$m^{p}=0.85 f_{\mathrm{c}} b a\left(d-\frac{1}{2} a\right)+A_{s}^{\prime} f_{\mathrm{y}}\left(d-d^{\prime}\right)$

where $d^{\prime}$ is the distance of the compression steel centroid from the tensile face, $A_{s}^{\prime}$ is the compression steel cross-section area, and

$a=\frac{\left(A_{s}-A_{s}^{\prime}\right) f_{\mathrm{y}}}{0.85 f_{\mathrm{c}} b}$

However, if we consider a typical moment-curvature diagram of a reinforced concrete beam (Fig. 4), a critical bending moment $m_{\mathrm{cr}}$ can be observed at a relatively small load, usually $1 / 6$ to $1 / 4$ of the maximum service load, which indicates the beginning of cracking at the tensile face. This moment can be calculated from Eqs. (47) or (48) by setting the

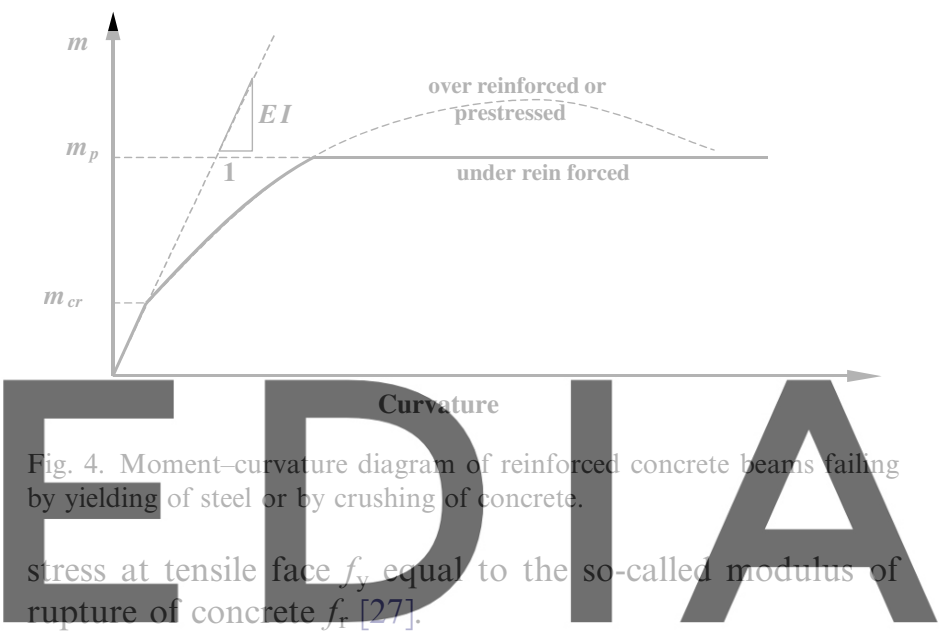

The plastic moment $m_{\mathrm{p}}$ is used to determine the plastic

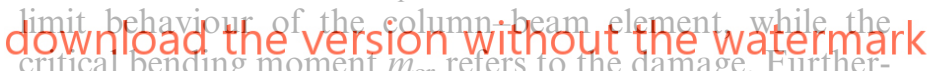
more, the elastic modulus $E$ is calculated by using Voigt's homogenization hypothesis [28] and the mixing theory [29], which supposes that all the materials have a perfect adherence each to other, leading to the following equivalent elastic modulus:

$E=(1-\rho) E_{\mathrm{c}}+\rho E_{s}$

\section{Member and global damage indices}

\subsection{Member damage index}

The idea for the member damage index definition stemmed from a macroscale analogy with the continuous damage model definition. The starting point for its deduction is the assumption that we can express the plastic-damage free energy of a member $\Psi_{b}\left(\boldsymbol{\Phi}_{b}^{e}, \mathbf{D}^{b}, q^{p}\right)=\Psi_{b}^{e}$, $\boldsymbol{\Phi}_{b}^{e}, \mathbf{D}^{b}+\Psi_{b}^{p}\left(q^{p}\right)$ of Eq. (44) in function of the non-damaged free energy, $\Psi^{0}$, defined by Eq. (27), as

$\Psi_{b}^{e}\left(\boldsymbol{\Phi}_{b}^{e}, \mathbf{D}^{b}\right)=\left(1-D_{M}^{b}\right) \boldsymbol{\Psi}_{b}^{0}$;

$\left\{\begin{array}{l}\Psi_{b}^{e}\left(\boldsymbol{\Phi}_{b}^{e}, \mathbf{D}^{b}\right)=\frac{1}{2} \boldsymbol{\Phi}_{b}^{e} \cdot \mathbf{S}_{b}^{d}\left(\mathbf{D}^{b}\right) \cdot \boldsymbol{\Phi}_{b}^{e} \\ \Psi_{b}^{0}\left(\mathbf{\Phi}_{b}^{e}\right)=\frac{1}{2} \boldsymbol{\Phi}_{b}^{e} \cdot \mathbf{S}_{b}^{0} \cdot \boldsymbol{\Phi}_{b}^{e}\end{array}\right.$

where $D_{M}^{b}$ is the member damage index. 
Solving (51) for $D_{M}^{b}$, we obtain

$D_{M}^{b}=1-\frac{\Psi_{b}^{e}\left(\boldsymbol{\Phi}_{b}^{e}, \mathbf{D}^{b}\right)}{\Psi_{b}^{0}}$

which is the expression of the damage index for the member of a frame. We can notice in Eq. (52) that for those cases where only damage is considered, that is $\boldsymbol{\Phi}_{b}^{p}=0$, we obtain that $D_{M}^{b}$ indicates the evolution of the concentrated damage at the hinges. Otherwise, when we have only plasticity, that is $\mathbf{D}^{b}=0, D_{M}^{b}$ indicates the increment of the plasticity at the hinges.

\subsection{Global damage index}

The global damage index is defined as the sum of $\Psi_{b}^{e}\left(\Phi_{b}^{e}, \mathbf{D}^{b}\right)$ divided by the sum of the non-damaged free energy $\Psi_{b}^{0}$

$$
\begin{aligned}
D_{\mathrm{G}} & =1-\frac{\sum_{b=1}^{3 n} \Psi_{b}^{e}\left(\boldsymbol{\Phi}_{b}^{e}, \mathbf{D}^{b}\right)}{\sum_{b=1}^{3 n} \Psi_{b}^{0}} \\
& =1-\frac{\sum_{b=1}^{3 n}\left(\boldsymbol{\Phi}_{b}-\boldsymbol{\Phi}_{b}^{p}\right) \cdot \mathbf{S}_{b}^{d}\left(\mathbf{D}^{b}\right) \cdot\left(\boldsymbol{\Phi}_{b}-\boldsymbol{\Phi}_{b}^{p}\right)}{\sum_{b=1}^{3 n} \boldsymbol{\Phi}_{b}^{e}: \mathbf{S}_{b}^{0}: \boldsymbol{\Phi}_{b}^{e}}
\end{aligned}
$$

where $D_{\mathrm{G}}$ is the global damage index. Replacing $\mathbf{M}_{b}^{0}=\mathbf{S}_{b}^{e}: \boldsymbol{\Phi}_{b}^{e}$, as well as $\boldsymbol{M}_{b}=\mathbf{S}_{b}^{d}\left(\mathbf{D}^{b}\right):\left(\boldsymbol{\Phi}_{b}-\boldsymbol{\Phi}_{b}^{p}\right)$, the following equation is obtained:

$D_{\mathrm{G}}=1-\frac{\sum_{b=1}^{3 n t h} \boldsymbol{\Phi}_{b}^{e}: \boldsymbol{M}_{b}}{\sum_{b=1}^{3 n t h} \boldsymbol{\Phi}_{b}^{e}: \boldsymbol{M}_{b}^{0}}$

This global damage index is similar to that proposed by $[6,30]$ for finite element analysis.

The global damage index, as well as the member damage index, is a basic tool for assessing the overall state of a structure. It gives a measure of the stiffness loss of a

Table 1

Non-linear time integration scheme (Newmark)

A. First iteration (passage from time instant $i$ to time instant $i+1$ )

i. Update relevant matrices
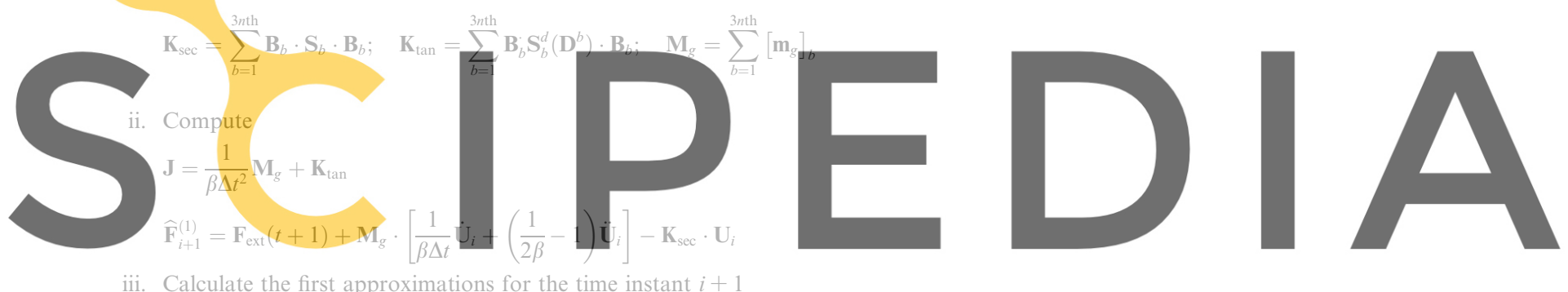

Register for free at https//.www.seipedia. \&om to download the version without the watermark

$$
\Delta \mathbf{u}_{i+1}^{(1)}=J^{-1} \widehat{\mathbb{F}}_{i+1}^{(1)}\left\{\begin{array}{l}
\dot{U}_{i+1}^{(1)}=\frac{\gamma}{\beta \Delta t} \Delta \mathrm{u}_{i+1}^{(1)}-\left(1-\frac{\gamma}{\beta}\right) \dot{\mathbf{U}}_{i}-\left(1-\frac{1}{2 \beta}\right) \Delta t \ddot{\mathbf{U}}_{i} \\
\mathbf{U}_{i+1}^{(1)}=\mathbf{U}_{i}+\Delta \mathbf{u}_{i+1}^{(1)}
\end{array}\right.
$$

B. Second and subsequent iterations (seeking the equilibrium for the time $i+1$ )

Loop over global convergence iterations: $j$ th iteration

1. Compute the member stresses and the internal variables

$$
\left[\boldsymbol{M}_{b}\right]_{i+1}^{j}=\left[\mathbf{S}\left(\mathbf{D}^{b}\right)_{i+1}^{j}\right] \cdot\left(\left\{\boldsymbol{\Phi}_{b}\right\}_{i+1}^{j}-\left\{\boldsymbol{\Phi}_{b}^{p}\right\}_{i+1}^{j}\right)
$$

2. Update relevant matrices

$$
\begin{aligned}
& \mathbf{F}_{\text {int }}^{(j)}=\left(\sum_{b=1}^{3 n \text {th }} \mathbf{B}_{b}: M_{b}\right) \cdot \mathbf{U}_{i+1}^{(j)} ; \quad \mathbf{K}_{\mathrm{tan}}=\sum_{b=1}^{3 n \text {th }} \mathbf{B}_{b} \cdot \mathbf{S}_{b}^{d}\left(\mathbf{D}^{b}\right) \cdot \mathbf{B}_{b} \\
& \mathbf{J}=\frac{1}{\beta \Delta t^{2}} \mathbf{M}_{g}+\mathbf{K}_{\mathrm{tan}} \\
& \widehat{\mathbf{F}}_{i+1}^{(j+1)}=\mathbf{F}_{\text {int }}(t+1)-\mathbf{M}_{g} \cdot \ddot{\mathbf{U}}_{i+1}^{(j)}-\mathbf{F}_{\text {int }}^{(j)}
\end{aligned}
$$

3. If the residual forces norm $\left\|\widehat{\mathbf{F}}_{i+1}^{(j+1)}\right\| \leqslant \varepsilon$, end of iterations and beginning of the computations in the next time step. If not, proceed calculating:

$$
\delta \mathbf{u}_{i+1}^{(j+1)}=\mathbf{J}^{-1}: \widehat{\mathbf{F}}_{i+1}^{(j+1)}\left\{\begin{array}{l}
\ddot{\mathbf{U}}_{i+1}^{(j+1)}=\frac{1}{\beta \Delta t^{2}} \delta \mathbf{u}_{i+1}^{(j+1)}+\ddot{\mathbf{U}}_{i+1}^{(j)} \\
\dot{\mathbf{U}}_{i+1}^{(j+1)}=\frac{\gamma}{\beta \Delta t} \delta \mathbf{u}_{i+1}^{(j+1)}+\dot{\mathbf{U}}_{i+1}^{(j)} \\
\mathbf{U}_{i+1}^{(j+1)}=\mathbf{U}_{i+1}^{(j)}+\delta \mathbf{u}_{i+1}^{(j+1)}
\end{array}\right.
$$


structure since the non-linear internal forces are influenced not only by the damage but also by the plasticity.

\section{Numerical implementation of the plastic-damage model}

The implementation process of the proposed plasticdamage model in a matrix structural analysis computer program is explained in Tables 1 and 2. The implicit time integration scheme of Newmark for dynamic non-linear problems is described by [31]. The most important results obtained by using the structural analysis computer program which has been developed in the present work based on the proposed model are: generalized strains $\boldsymbol{\Phi}_{b}$, stresses $\boldsymbol{M}_{b}$, plastic strains $\boldsymbol{\Phi}_{b}^{p}$ and/or concentrated damage vector $\mathbf{D}^{b}$, member damage indices and the global damage index. If necessary, the remaining internal variables and their associated forces can be also obtained for each member of the structure. These results are obtained by using the

Table 2

Procedure to determine the evolutions of the damage and plastic variables

For each $b$ elements at $n$th iteration:

1. Generalized deformations at the step: $\left\{\boldsymbol{\Phi}_{b}\right\}_{t}^{(n)}=\left[\mathbf{B}_{b}\right]:\{\mathbf{U}\}_{t}^{(n)}$

2. Verification of the damage variable evolution:

i. Update the internal variables: $\left\{\mathbf{D}^{b}\right\}_{t}^{(n)}=\left\{\mathbf{D}^{b}\right\}_{t}^{(n-1)} ;\left\{r_{k}^{b}\right\}_{t}^{(n)}=\left\{r_{k}^{b}\right\}_{t}^{(n-1)}$

ii. Determination of the undamaged energy norm vector:

$$
\left\{\tau_{k}^{b}\right\}_{t}^{(n)}=\left[\sqrt{\left\{\boldsymbol{\Phi}_{b}\right\}_{t}^{(n)} \cdot \mathbf{S}_{b} \cdot\left\{\boldsymbol{\Phi}_{b}\right\}_{t}^{(n)}}\right]_{k} \quad \forall k \in(i, j, \delta)
$$

iii. Verification of the evolution of the damage:

If $g_{k}\left(\tau_{k}^{b}, r_{k}^{b}\right)_{t}^{(n)} \leqslant 0 ; \quad \forall k \in(i, j, \delta)$ No damage evolution 3

iv. Update damage variable: $\left\{\mathbf{D}^{b}\right\}_{t}^{(n)}=G\left(\tau_{k}^{b}\right)_{t}^{(n)}$

v. Update damage threshold: $\left(r_{k}^{b}\right)_{t}^{(n)}=\left(\tau_{k}^{b}\right)_{t}^{(n)}$

3. Verification of the plastic variable evolution for $s=s+1$ iterative step:

i. Determination of plastic evolution and update of internal variables:

$$
\left\{\Delta \boldsymbol{\Phi}_{b}^{p}\right\}_{0}=\left\{\boldsymbol{\Phi}_{b}^{p}\right\}_{t}^{(n-1)} ; \quad\left\{\Delta q^{p}\right\}_{0}=\left\{q^{p}\right\}_{t}^{(n-1)}
$$

ii. Determination of generalized effective 'trial' stress:

$$
\left\{\mathbf{M}_{b}^{\text {trial }}\right\}_{s}=\mathbf{S}_{b} \cdot\left(\left\{\boldsymbol{\Phi}_{b}\right\}_{t}^{(n)}-\left\{\Delta \boldsymbol{\Phi}_{b}^{p}\right\}_{s-1}\right)
$$

iii. Verification of flow conditions and determination of plastic multiplier

$$
\begin{array}{lll}
\left(\dot{\lambda}_{i}^{p}\right)_{s}=0 & \text { if } f\left[\left(m_{i}^{\text {trial }}\right)_{s-1}-\left(\Delta q^{p}\right)_{s-1}\right]_{i}<0 \text { or }\left(\lambda_{i}^{p}\right)_{s}\left[\dot{f}_{i}\right]_{s-1}<0 \\
\left(\dot{\lambda}_{j}^{p}\right)_{s}=0 & \text { if } f\left[\left(m_{j}^{\text {trial }}\right)_{s-1}-\left(\Delta q^{p}\right)_{s-1}\right]_{j}<0 \text { or }\left(\lambda_{j}^{p}\right)_{s}\left[\dot{f}_{j}\right]_{s-1}<0 & \text { No plasticity evolution } \rightarrow 4 . \\
& \\
\left(\dot{\lambda}_{i}^{p}\right)_{s} \neq 0 & \text { if } f\left[\left(m_{i}^{\text {trial }}\right)_{s-1}-\left(\Delta q^{p}\right)_{s-1}\right]_{i}=0 \text { or }\left(\lambda_{i}^{p}\right)_{s}\left[\dot{f}_{i}\right]_{s-1}=0 & \\
\left(\dot{\lambda}_{j}^{p}\right)_{s} \neq 0 & \text { if } f\left[\left(m_{i}^{\text {trial }}\right)_{s-1}-\left(\Delta q^{p}\right)_{s-1}\right]_{j}=0 \text { or }\left(\lambda_{j}^{p}\right)_{s}\left[\dot{f}_{j}\right]_{s-1}=0 & \text { Plastic evolution } \rightarrow 3 .
\end{array}
$$

iv. Update of plastic variables and of the generalized effective 'trial' stress:

$$
\begin{aligned}
& \left(\dot{\phi}_{i}^{p}\right)_{s}=\left(\dot{\lambda}_{i}^{p}\right)_{s}\left(\frac{\partial f_{i}}{\partial m_{i}}\right)_{s-1}\left(\dot{\phi}_{j}^{p}\right)_{s}=\left(\dot{\lambda}_{j}^{p}\right)_{s}\left(\frac{\partial f_{j}}{\partial m_{j}}\right)_{s-1}\left(\dot{\delta}^{p}\right)_{s}=\left(\dot{\lambda}_{i}^{p}\right)_{s}\left(\frac{\partial f_{i}}{\partial n}\right)_{s-1}+\dot{\lambda}_{j}^{p}\left(\frac{\partial f_{j}}{\partial n}\right)_{s-1} \\
& \left(m_{i}^{\text {trial }}\right)_{s}=\left(m_{i}^{\text {trial }}\right)_{s-1}-\left(\dot{\lambda}_{i}^{p}\right)_{s} \mathbf{S}_{b} \cdot\left\{\frac{\partial f_{i}}{\partial m_{i}^{\text {trial }}}\right\}_{s-1} ; \quad\left(m_{j}^{\text {trial }}\right)_{s}=\left(m_{j}^{\text {trial }}\right)_{s-1}-\left(\dot{\lambda}_{j}^{p}\right)_{s} \mathbf{S}_{b} \cdot\left\{\frac{\partial f_{j}}{\partial m_{j}^{\text {trial }}}\right\}_{s-1} \\
& \left(n^{\text {trial }}\right)_{s}=\left(n^{\text {trial }}\right)_{s-1}-\left(\left(\dot{\lambda}_{i}^{p}\right)_{s} \mathbf{S}_{b} \cdot\left\{\frac{\partial f_{i}}{\partial n^{\text {trial }}}\right\}_{s-1}+\left(\dot{\lambda}_{j}^{p}\right)_{s} \mathbf{S}_{b} \cdot\left\{\frac{\partial f_{j}}{\partial n^{\text {trial }}}\right\}_{s-1}\right)
\end{aligned}
$$

v. Back to 3.ii

4. End of the process of plastic correction

$$
\left\{\boldsymbol{\Phi}_{b}^{p}\right\}_{t}^{(n)}=\left\{\Delta \boldsymbol{\Phi}_{b}^{p}\right\}_{s} ; \quad\left\{q^{p}\right\}_{t}^{(n)}=\left\{\Delta q^{p}\right\}_{s}
$$

5. Achievement of the final generalized stress on the step $n$ :

$$
\left\{\boldsymbol{M}_{b}\right\}_{t}^{(n)}=\left[\mathbf{S}_{b}\left(\mathbf{D}^{b}\right)_{t}^{(n)}\right] \cdot\left(\left\{\boldsymbol{\Phi}_{b}\right\}_{t}^{(n)}-\left\{\boldsymbol{\Phi}_{b}^{p}\right\}_{t}^{(n)}\right)
$$



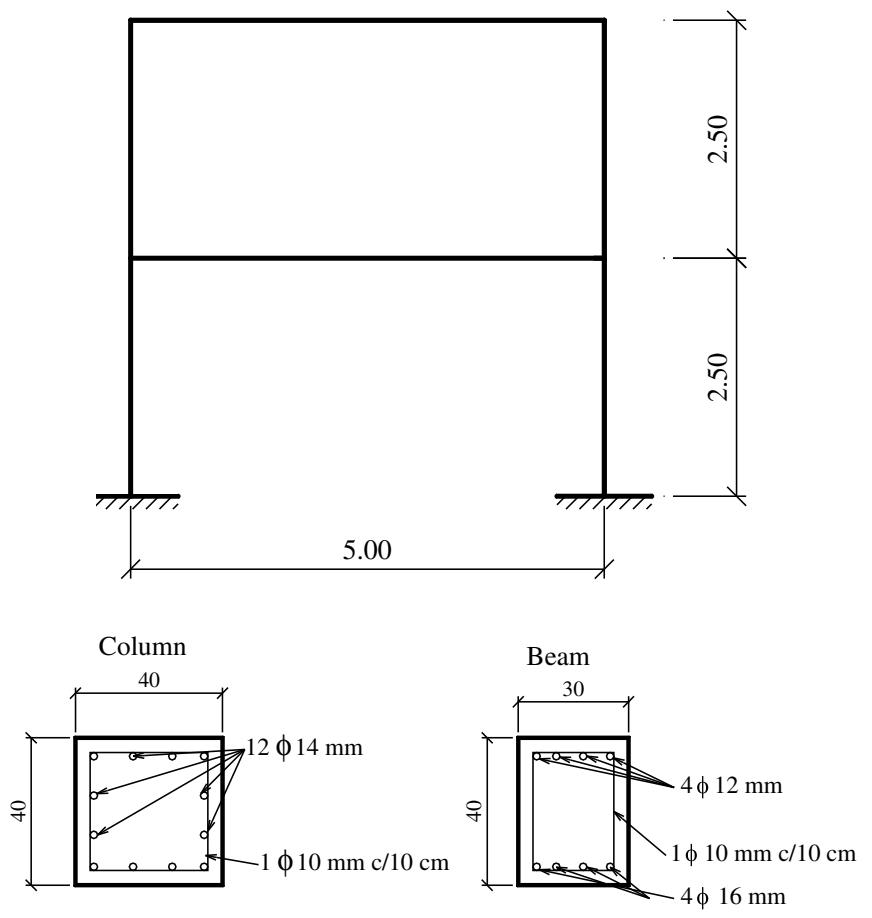

Fig. 5. Geometry and sections of the studied frame.

equilibrium equations (9) together with the constitutive law (45) in accordance with the internal variables evolution laws (15) and (16).

Let us now focus our attention on the calculation of the member stresses and of the internal variables (Table 1). The plastic and damage parameters can be calculated separately, as explained in Section 5. This assumption comes from the observation that damage is linked to the concrete, while plastification is related to the steel. Therefore, the damage evolution can be determined by

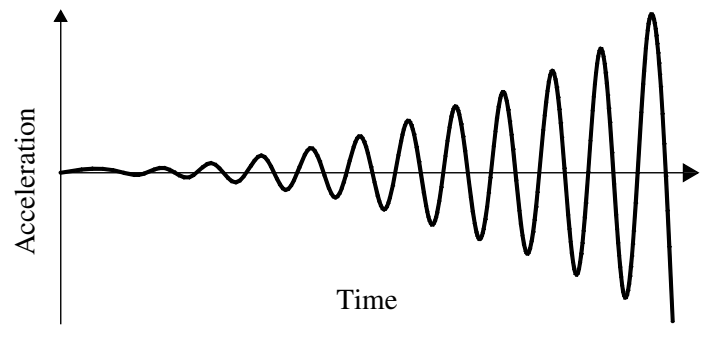

Fig. 6. Dynamic load.

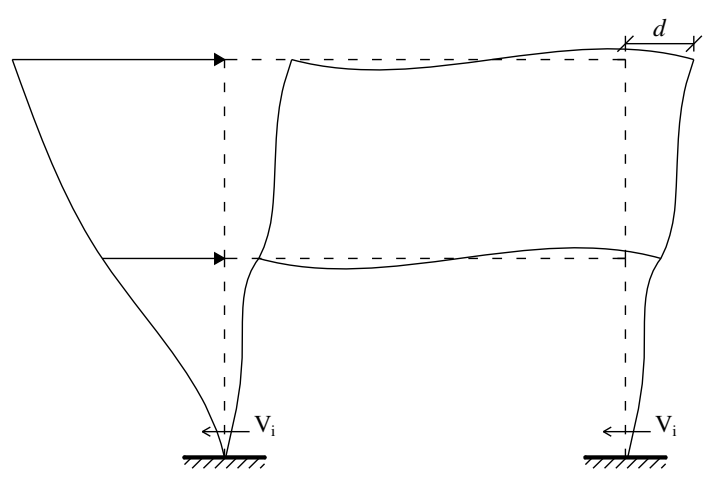

Fig. 7. Pushover loading pattern.

Eqs. (29)-(31) and the plastic behaviour by means of Eq. (13).

\section{Numerical examples}

\subsection{Example 1: Pushover and dynamic analysis of a reinforced concrete frame}

This validation example compares the evolutions of the global damage indices in the reinforced concrete plane

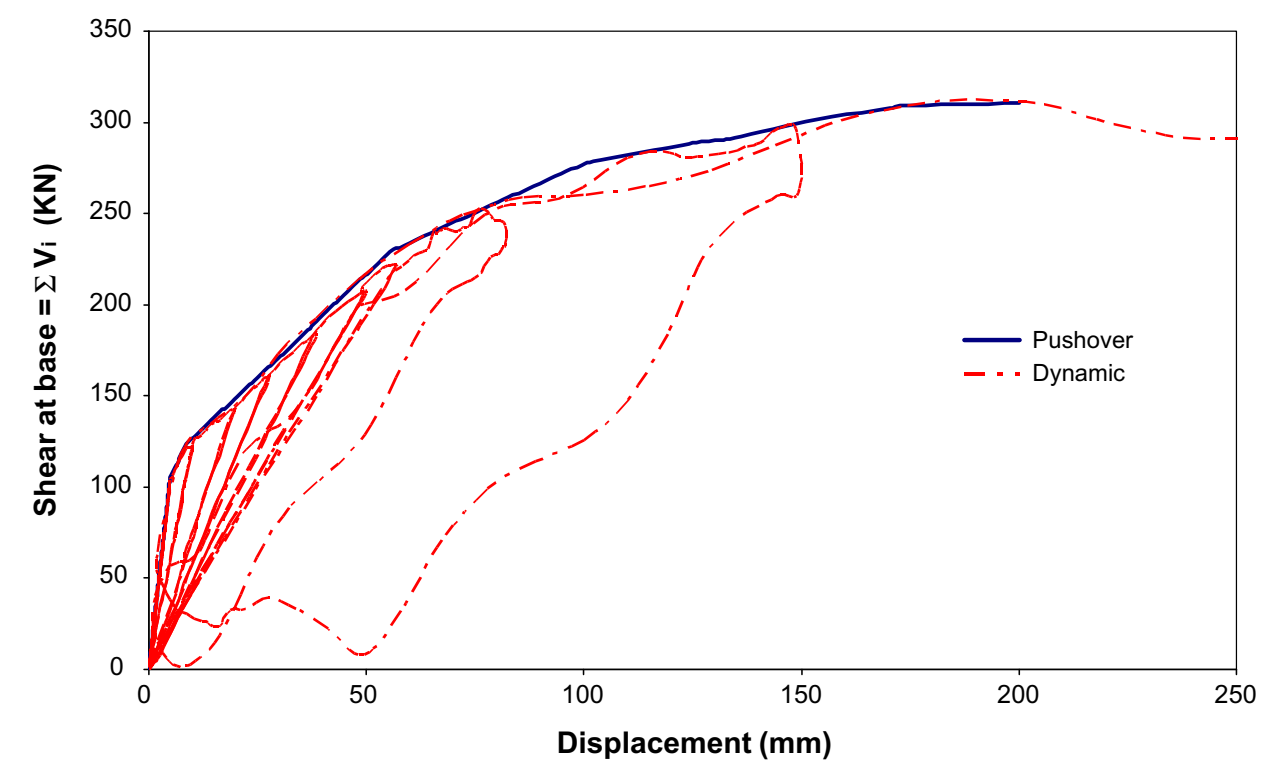

Fig. 8. Base shear versus global structural drift. 


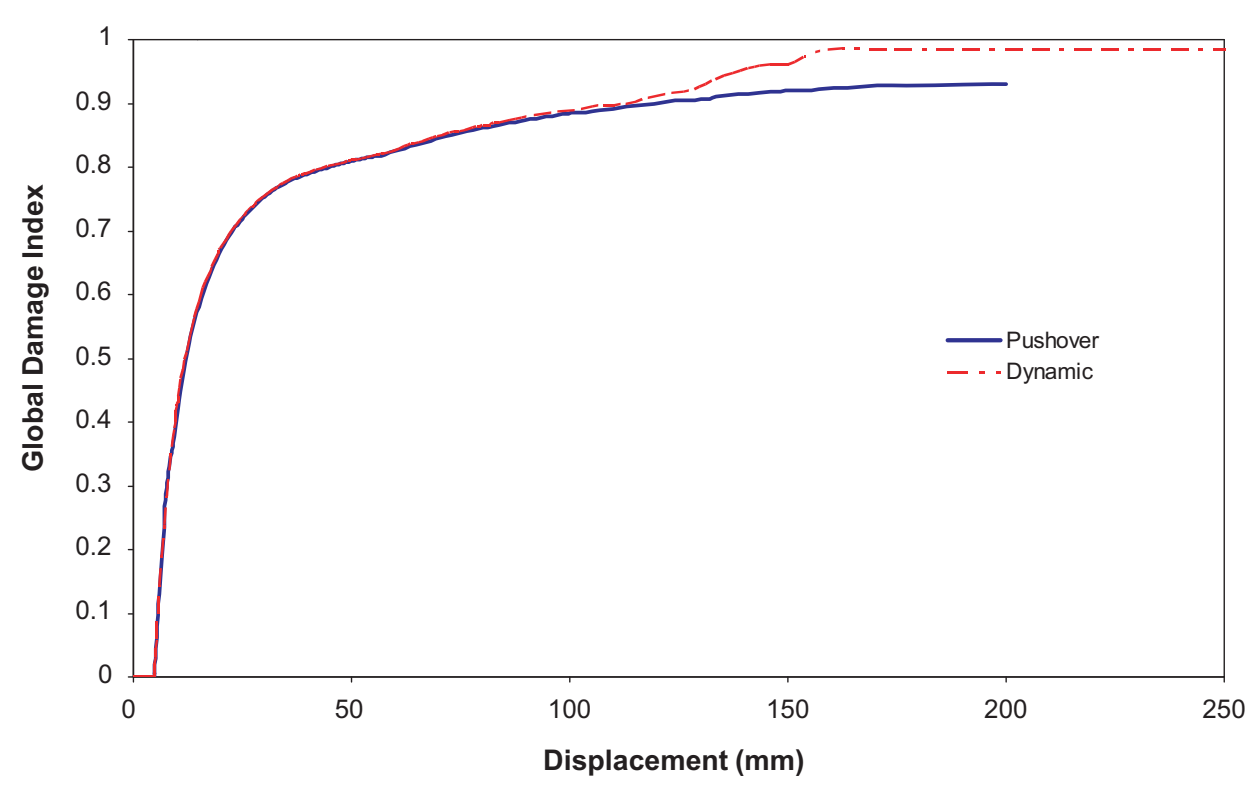

Fig. 9. Global damage evolution.

frame of Fig. 5 when subjected to horizontal loads (pushover analysis) and dynamic loads.

The frame is $5 \mathrm{~m}$ high and $5 \mathrm{~m}$ wide and has two levels. The columns have a $0.40 \mathrm{~m} \times 0.40 \mathrm{~cm}$ cross-section with a steel ratio of $1.9 \%$. The critical and ultimate moments are $m_{\mathrm{cr}}=30 \mathrm{kN} \mathrm{m}$ and $m_{\mathrm{u}}=182 \mathrm{kN} \mathrm{m}$, respectively. All the horizontal beams are $0.40 \mathrm{~m}$ thick and $0.30 \mathrm{~m}$ wide, with a steel ratio of $0.75 \%$ at bottom and $0.42 \%$ at top, as shown in Fig. 5. For the beams, the adopted critical and ultimate moments are $m_{\mathrm{cr}}=18 \mathrm{kN} \mathrm{m}$ and $m_{\mathrm{u}}=111 \mathrm{kN} \mathrm{m}$, respectively. The reinforced concrete is assume to have the following properties: compressive strength $\sigma=21 \mathrm{MPa}$, elastic modulus $E=3.1 \times 10^{4} \mathrm{MPa}$, density $\rho_{0}=2.5 \mathrm{kN} /$ $\mathrm{m}^{3}$ and a fracture energy $G_{\mathrm{f}}$ equal to $250 \mathrm{kN} / \mathrm{m}$. The steel has a hardening plastic modulus equal to $10^{2} \mathrm{MPa}$. The time history of the dynamic load is given in Fig. 6 while the pushover loading pattern can be seen in Fig. 7 .

The conventional pushover analysis searches the nonlinear incremental-iterative solution of the equilibrium equation $[\mathbf{K}]\{\mathbf{U}\}=\{\mathbf{F}\}$, where $\{\mathbf{U}\}$ is the displacement vector, $[\mathbf{K}]=\sum\left[\mathbf{B}_{b}^{t}\right]:\left[\mathbf{S}_{b}^{d}\left(\mathbf{D}_{b}\right)\right]:\left[\mathbf{B}_{b}\right]$ is the non-linear stiffness matrix and $\{\mathbf{F}\}$ is a predefined load vector applied laterally along the height of the structure in relatively small load increments (see Fig. 7). This lateral load can be a set of forces or displacements with a fixed pattern which, in this example, corresponds to the first mode of vibration of the structure. The effect of the axial damage was neglected in this analysis because the objective was to describe only the evolution of the damage hinges produced by the flexural behaviour during earthquake loads.

The pushover analysis allows computing the sequence of yielding and failure at member and structural level, as well as the progress of the overall strength capacity of the structure, as shown in Fig. 8, The horizontal forces $\left(V_{i}\right)$ of the base nodes were plotted against the horizontal
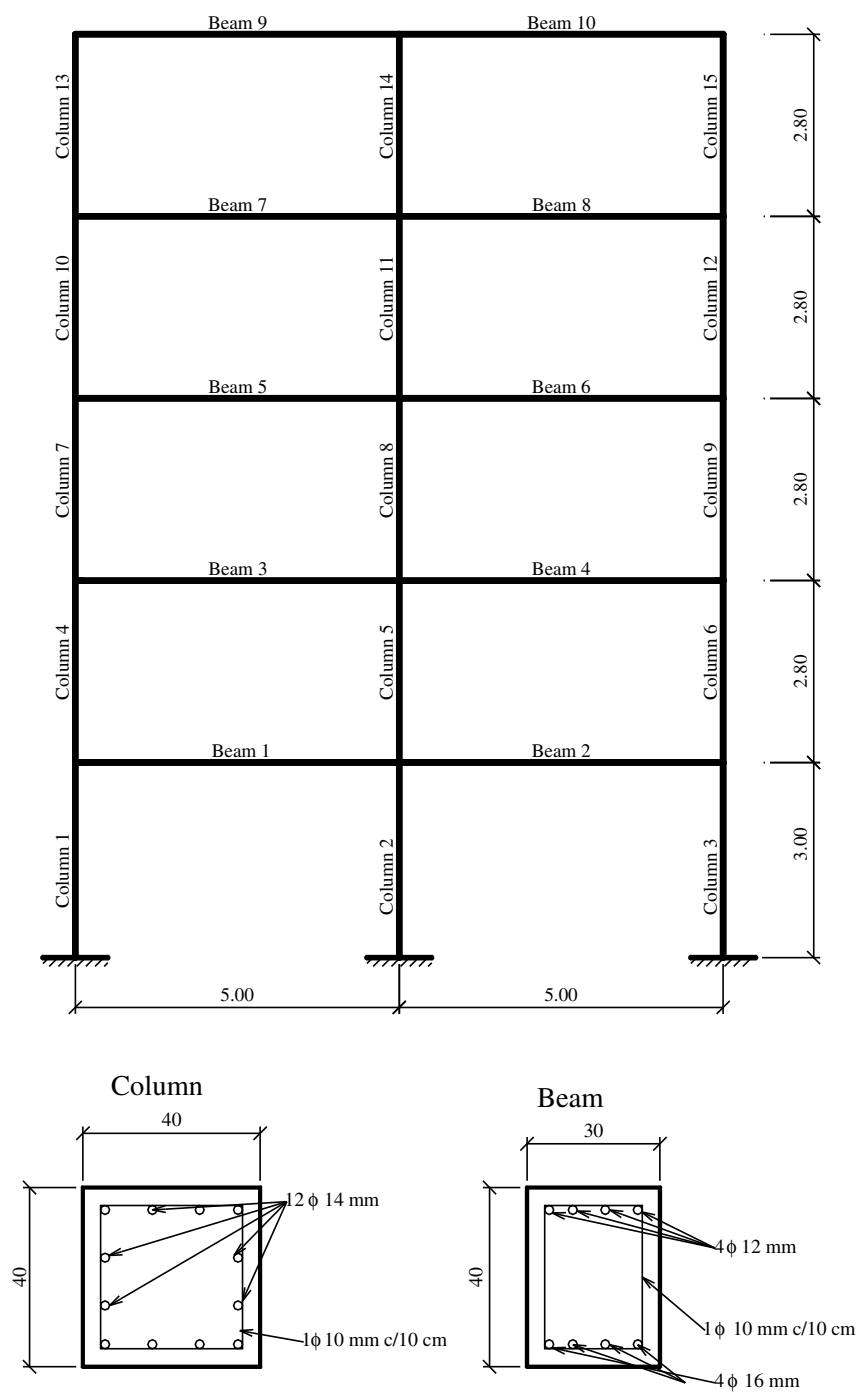

Fig. 10. Geometry and sections of the studied frame. 


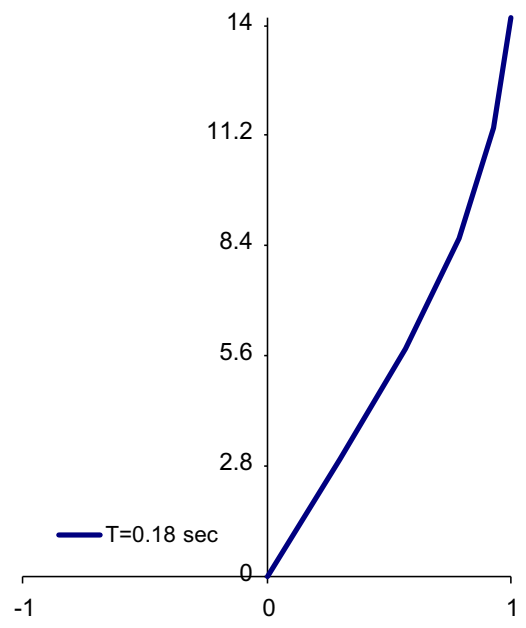

Mode 1

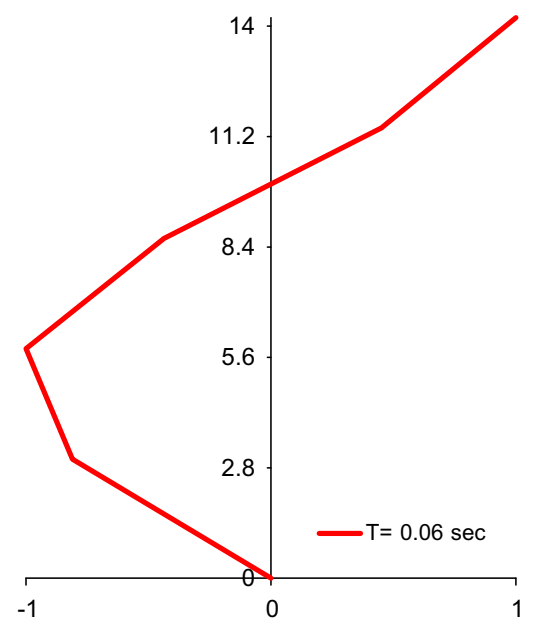

Mode 2

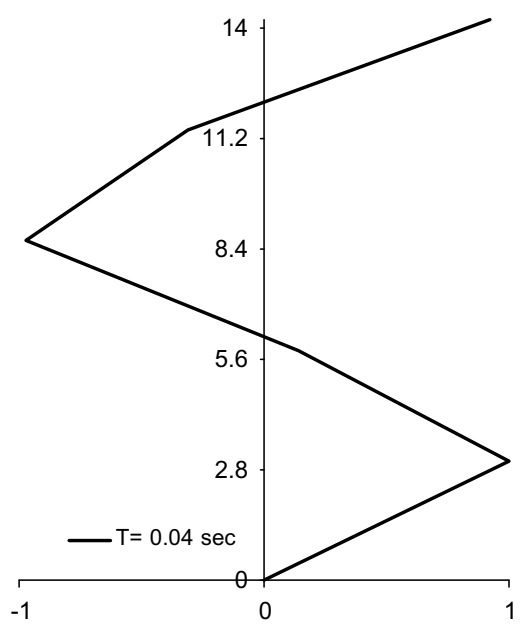

Mode 3

Fig. 11. Modal shapes and periods of the first three modes of vibration of the studied frame.

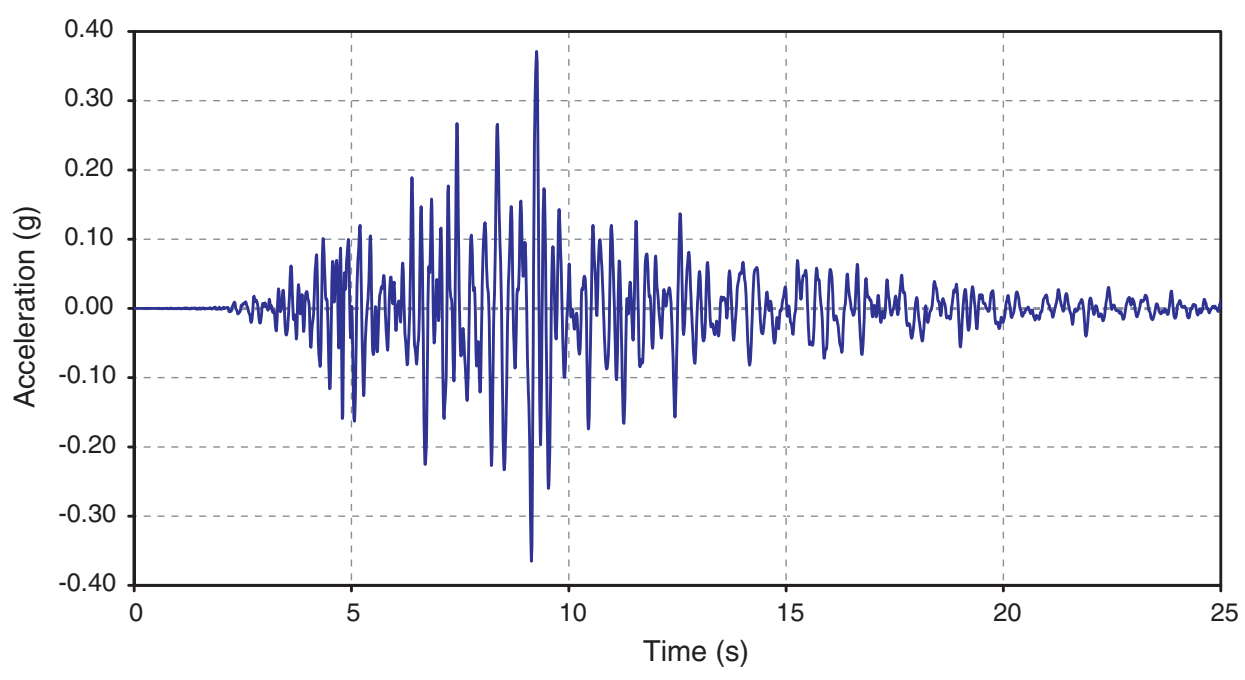

Fig. 12. Accelerogram of the Kobe, Japan, 1995 earthquake.

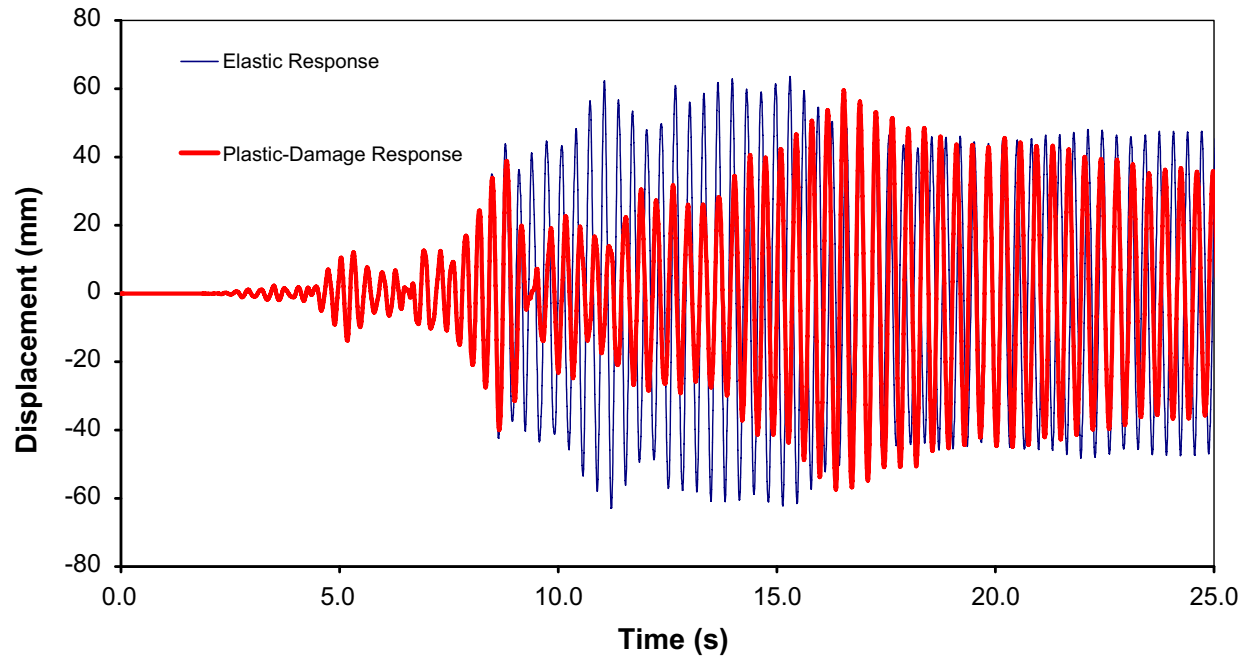

Fig. 13. Fifth floor displacements for elastic and plastic-damage behaviour of the structure. 
displacement of the top floor $d$ in Fig. 7. When a dynamic analysis is performed, the support displacement is subtracted from the top displacement in order to determine de global drift of the structure. The pushover curve enveloping the absolutes values of the dynamic response can be seen in Fig. 8.

Analyzing the evolution of the global damage index of Fig. 9, we can perceive that during the phase where the plasticity is null or irrelevant, both global damage curves, corresponding to the dynamic and pushover responses, are similar. However, the final value of the global damage obtained by means of the dynamic analysis is higher than the value of the global damage obtained by pushover analysis. This occurs because in the dynamic case the plasticity appears suddenly, while in the pushover analysis the influence of the plasticity is gradual. The static pushover analysis neglects the dynamic effects, while the conventional pushover analysis procedure does not account for the progressive changes in the modal properties during the nonlinear yielding and cracking process occurring in the structure. This is due to the fact that the constant lateral load pattern used in the analysis ignores the potential redistribu-

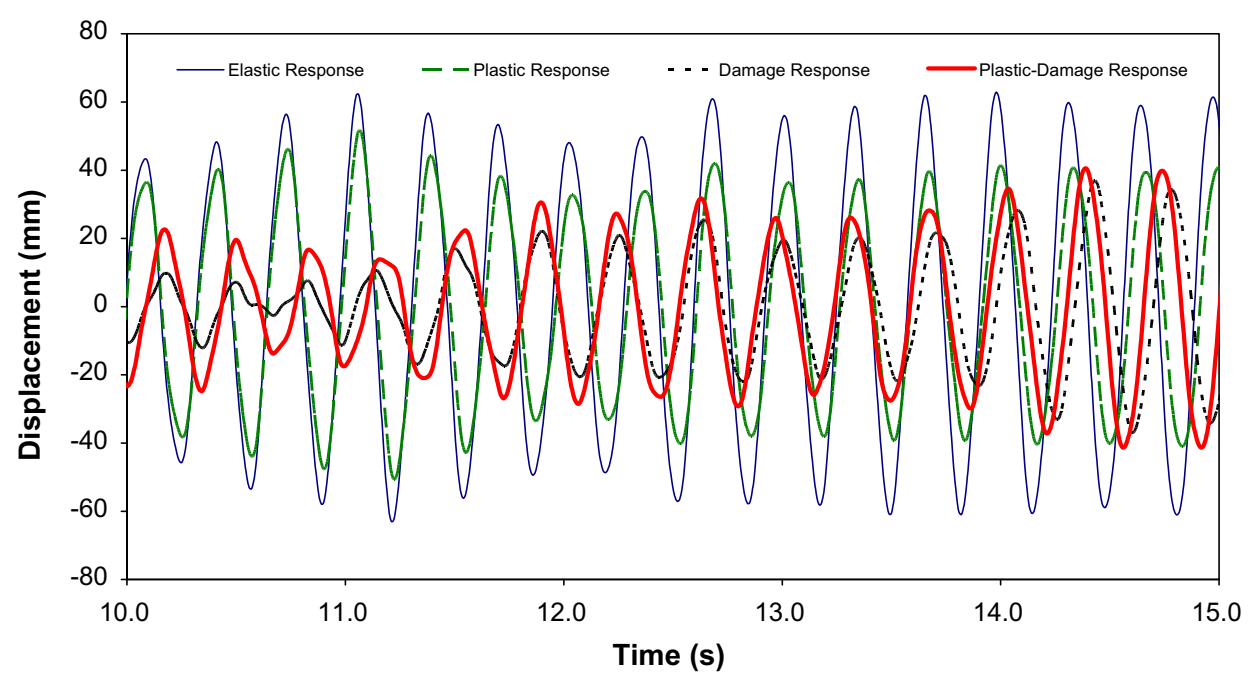

Fig. 14. Comparison of the elastic, plastic, damage and plastic-damage response of the structure.

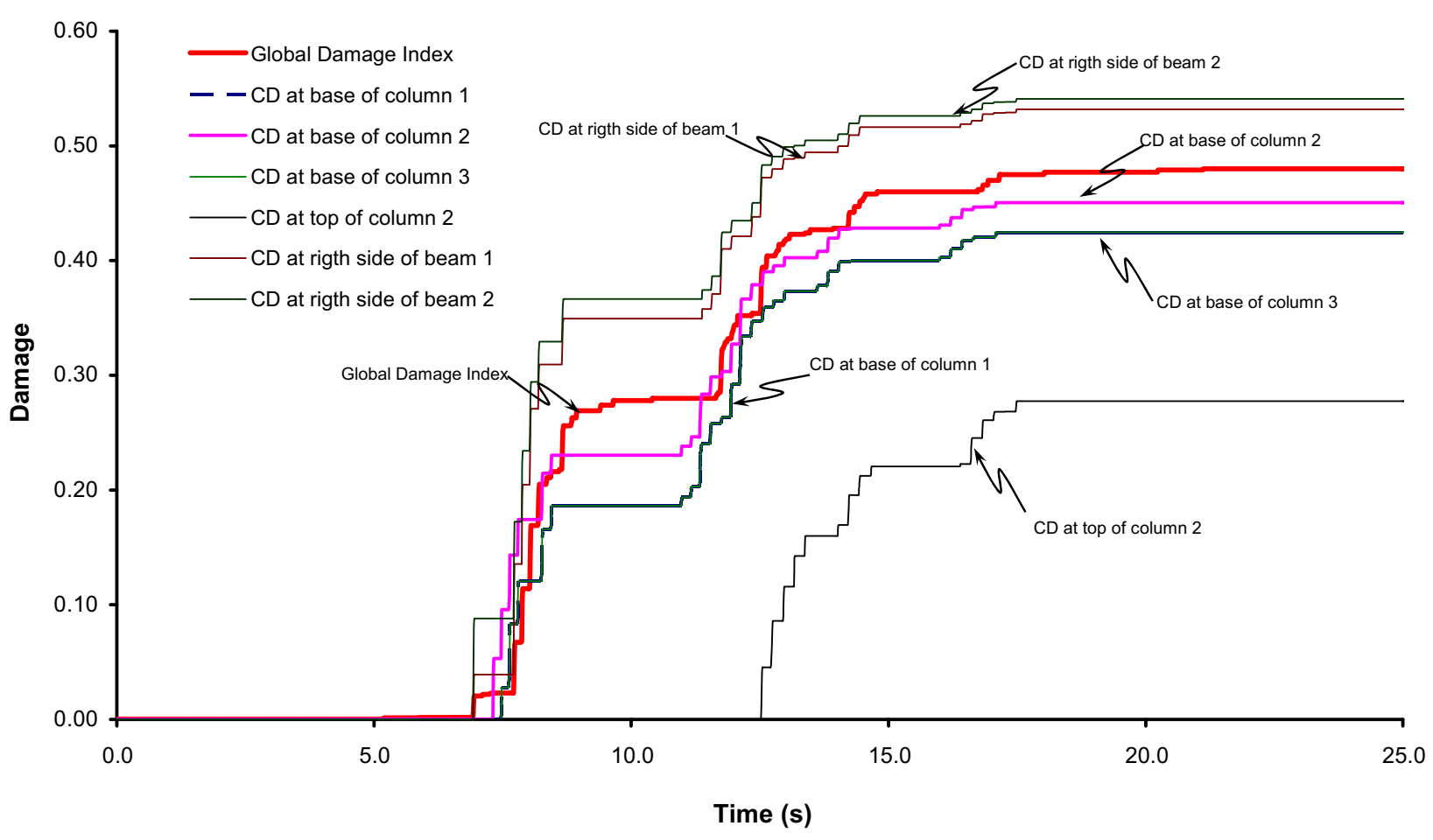

Fig. 15. Evolution of the global damage index and of the concentrated damage (CD) at the base and top of columns of the first floor. 
tion of inertia forces and the higher mode effects on the cracking and yielding which governs the inelastic structural behaviour. As a consequence, the energy dissipated by the plasticity during a dynamic action is higher than during the pushover response and affects directly the global damage index.

\subsection{Example 2: Reinforced concrete frame subjected to seismic acceleration}

This example studies the evolutions of the damage and plasticity process in the five floors of the reinforced concrete plane frame of Fig. 10 subjected to a seismic action. The

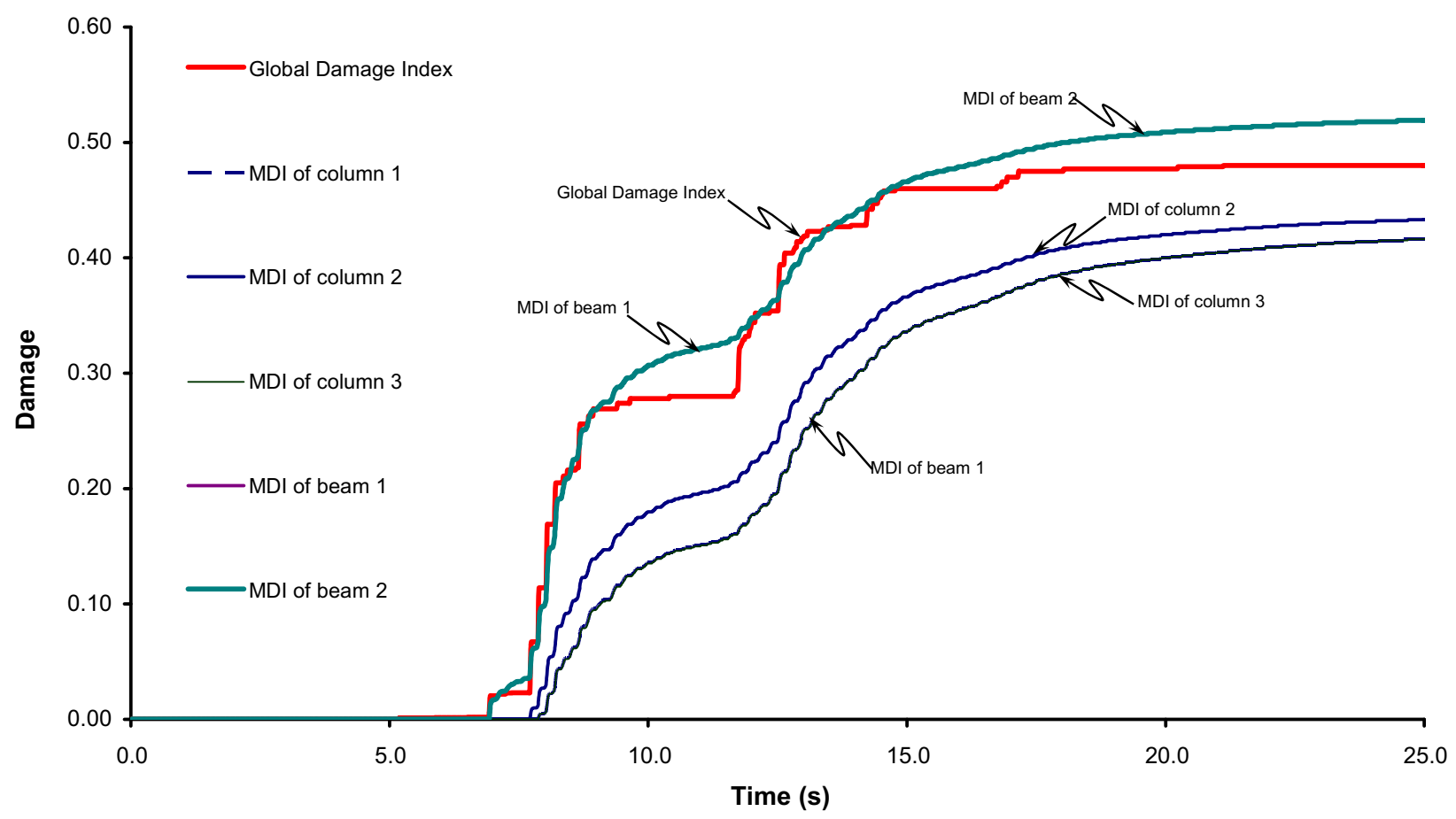

Fig. 16. Evolution of the global and member damage (MDI) indices for the first floor.

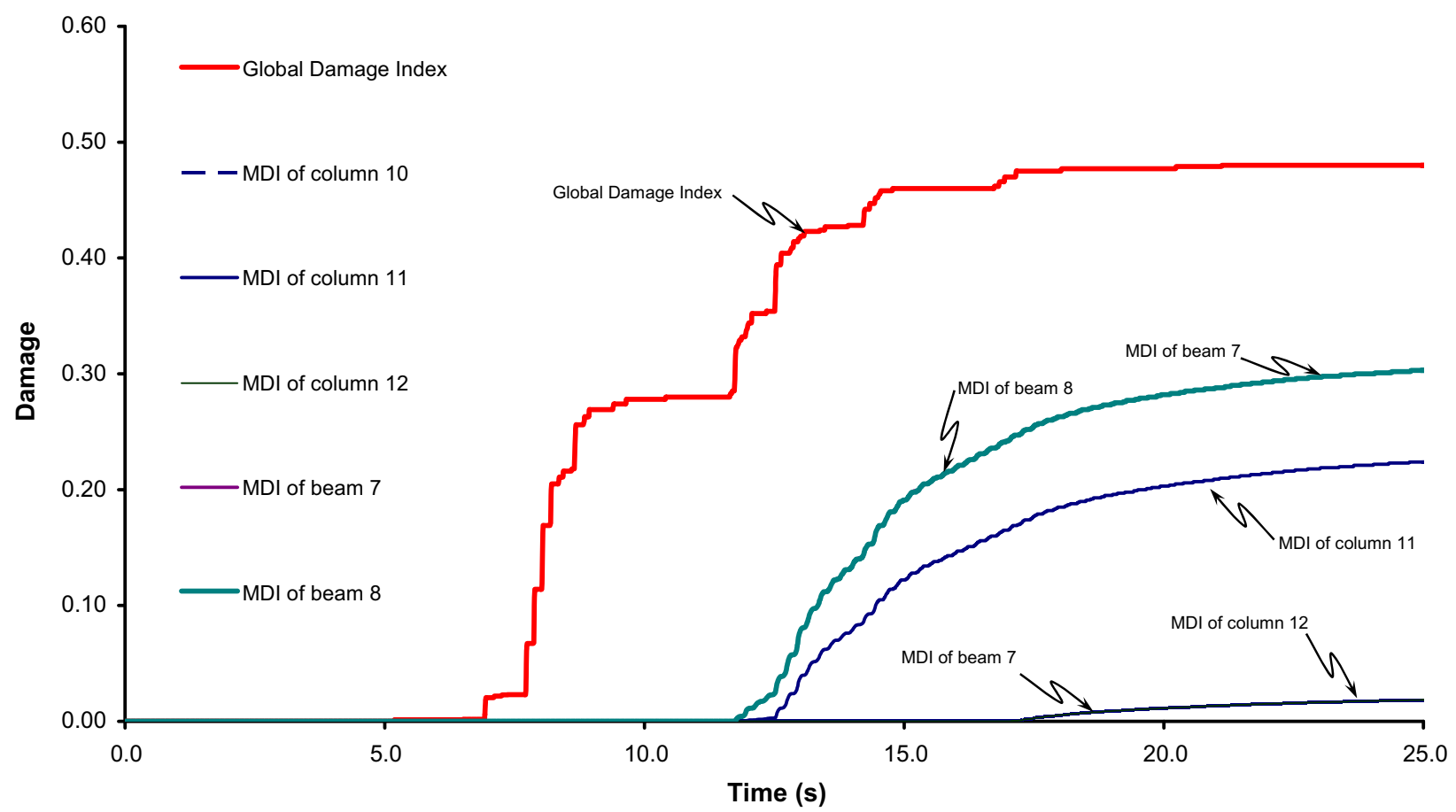

Fig. 17. Evolution of the global and member damage (MDI) indices for the fourth floor. 
frame is $12.5 \mathrm{~m}$ high and $10 \mathrm{~m}$ wide and has five levels. The columns have a $0.40 \mathrm{~m} \times 0.40 \mathrm{~m}$ cross-section with a $1.9 \%$ steel ratio. The critical and ultimate bending moments are $m_{\mathrm{cr}}=30 \mathrm{kN} \mathrm{m}$ and $m_{\mathrm{u}}=182 \mathrm{kN} \mathrm{m}$, respectively. All the horizontal beams are $0.40 \mathrm{~m}$ thick and $0.30 \mathrm{~m}$ wide, with a steel ratio of $0.75 \%$ at the bottom and $0.42 \%$ at the top, as shown in Fig. 10. The critical and ultimate moments of the beams are $m_{\mathrm{cr}}=18 \mathrm{kN} \mathrm{m}$ and $m_{\mathrm{u}}=111 \mathrm{kN} \mathrm{m}$, respectively. We assume the following properties of reinforced concrete: compressive strength $\sigma=21 \mathrm{MPa}$, elastic modulus $E=$ $3.1 \times 10^{4} \mathrm{MPa}$, density $\rho_{0}=2.5 \mathrm{kN} / \mathrm{m}^{3}$ and a fracture energy $G_{\mathrm{f}}=250 \mathrm{kN} / \mathrm{m}$. The steel has a hardening plastic modulus equal to $10^{2} \mathrm{MPa}$. Fig. 11 shows the modal shapes and natural periods of vibration for the first three modes of the frame.

The equation of motion that governs the dynamic behaviour of the structure has been solved using Newmark's algorithm of Table 1 with $\beta=0.25, \gamma=0.5$ and a time step $\Delta t=0.01 \mathrm{~s}$. The structure was analysed for the Kobe 1995 earthquake whose accelerogram is given in Fig. 12 and has a maximum amplitude of $0.371 \mathrm{~g}$.

Fig. 13 shows the comparison between the responses of the structure considering an elastic and plastic-damage behaviour of the material. The displacements correspond to the fifth floor.

In Fig. 14, we analyze the response of the structure during the period from seconds 10 to 15 and we include the damage and plastic response of the material. It can be observed in this figure that the damage and plastic-damage have initially almost the same period and similar to that of the elastic and plastic curves. We can also observe that when the plasticity increases, the period of the plastic-damage curve is higher than that of the damage and plastic responses.

The phase where only damage is shows the decrease of the vibration period of the structure and in this phase the response of the structure is similar to a damped one. This occurs because the damage works as a damping force. Afterwards, due to the combination of plasticity and damage, the structure behaves like an undamped system.

Fig. 15 shows the evolution of the concentrated damage in the first, second and third columns of the first floor, while Figs. 16 and 17 show the evolution of the global and member damage indices in the first and fourth floor, respectively. As expected, the frame fails mainly due to the damage of the columns at its base and of the beams of the first floor. This behaviour is confirmed by the evolution of the concentrated damage indices (Fig. 15).

By analyzing the evolution of the concentrated damage of the first floor columns, shown in Fig. 15, we can observe that the damages at the base of all the columns are less than the global damage and constantly increase in time, while the evolutions of the concentrated damage of the beams at the first floor are higher than the global damage index.

The same behaviour can be observed for the member damage indices of the first floor (see Fig. 16), where the mem- ber damage indices of the beams tend practically to the same value as the global damage index of the entire structure.

Comparing the member damage indices of the first floor (Fig. 16) and the fourth floor (Fig. 17), it can be observed that all damage indices decreases. This occurs because damage decreases with the height. It also can be observed that in all cases the damage starts first in the beams and later in the columns.

We can also notice that all damage indices of the beams are greater than those of the columns. This is in agreement with the desired behaviour of the structures under a seismic load in which, in order to assure structural ductility and safety, the beam should develop plastic hinges before the columns.

Additionally, due to the hardening adopted in this case, the global behaviour of the structure is not influenced by the plasticity because, even if all the members are yielding, member damage indices are not higher than the global damage index. This occurs because the hardening of the material can influence the member damage index and might not allow maximum plastic dissipation.

\section{Conclusions}

A general model for the non-linear analysis of frames based on the Continuum Damage Mechanics and Plasticity Theory has been developed. The plastic-damage model developed in this paper assumes that plasticity and damage are uncoupled, have their own laws and that both are concentrated at ends of the members of the frames.

The proposed model proves to be effective for the numerical simulation of the seismic collapse of frames. It is a valuable alternative when other types of analyse, such as those based on multi-layer models, appear to be too expensive or impractical due to the size and complexity of the structure. The proposed model for reinforced concrete frames exhibits a very good precision confirmed by the examples included in the paper.

As shown by the numerical examples for static or dynamic loads, the proposed model can represent accurately the real seismic behaviour of reinforced concrete structures. Another benefit of the proposed model is the simple implementation into a matrix analysis computer program, providing an efficient tool for the plastic-damage analysis of reinforced concrete frames.

The proposed member and global damage indices have proved to be a powerful and precise tool for identifying the failure load and the structural mechanism leading to failure of reinforced concrete framed structures. Theses indices allow an accurate quantitative evaluation of the state of any component of a damaged structure and of the overall seismic structural behaviour. It is an excellent tool for the seismic damage, reliability and safety assessment of exiting structures, which can be also used in the evaluation of the repair or retrofitting strategies. 


\section{References}

[1] Carreño ML, Cardona OD, Barbat AH. Urban seismic risk evaluation. Natural Hazards 2007;40:137-72.

[2] DiPasquale E, Çakmak AS. Detection of seismic structural damage using parameter-based global damage indices. Probabilistic Engineering Mechanics 1990;5(2):60-5.

[3] Park YJ, Ang AH. Mechanistic seismic damage model for reinforced concrete. J Struct Eng: ASCE 1985;111(4):722-39.

[4] Barbat AH, Oller S, Oñate E, Hanganu A. Viscous damage model for Timoshenko beam structures. Int J Solid Struct 1997;34(30):3953-76.

[5] Oller S, Barbat AH, Oñate E, Hanganu A. A damage model for the seismic analysis of building structures. In: Proceedings of the tenth world conference on earthquake engineering, Madrid, Spain. A.A. Balkema; 1992.

[6] Hanganu A, Oñate E, Barbat AH. A finite element methodology for local/global damage evaluation in civil engineering structures. Comput Struct 2002;80:1667-87.

[7] Kachanov LM. On creep rupture time. Proc Acad Sci USSR, Div Eng Sci 1958;8:26-31.

[8] Simo JC, Ju JW. Stress and strain based continuum damage models-I. Formulation. Int J Solid Struct 1987;23:821-40.

[9] Luccioni B, Oller S, Danesi R. Plastic damaged model for anisotropic materials. In: Fourth Pan American congress of applied mechanics (PACAM IV), Buenos Aires, 1995.

[10] Luccioni B, Oller S, Danesi R. Coupled plastic-damage model. Comput Method Appl Mech Eng 1996;129:81-9.

[11] Oller S, Barbat AH. Moment-curvature damage model for bridges subjected to seismic loads. Comput Method Appl Mech Eng 2006;195:4490-511.

[12] Massonnet CE, Save MA. Cálculo plástico de las construcciones. 1966, Barcelona: Montaner y Simón, DL.

[13] Deierlein GG, Hajjar JF, Kavinde A. Material nonlienar analysis of strucutres: a concentrated plasticity approach. In: Report SE, editor. Department of Civil Engineering, University of Minesota, 2001. http://cee.engr.ucdavis.edu/faculty/kanvinde/concenplast.pdf.

[14] Cipolina A, López Inojosa A, Flórez-López J. A simplified damage mechanics approach to non-linear analysis of frames. Comput Struct 1995;54(6):1113-26.

[15] Flórez-López J. Simplified model of unilateral damage for RC frames. J Struct Eng: ASCE 1995;121(12):1765-71.

[16] Faleiro J, Barbat AH, Oller S. Plastic damage model for non-linear reinforced concrete frame analysis. In: VIII international conference on computational plasticity (COMPLAS VIII), Barcelona - Spain, 2005. www.cimne.upc.edu.

[17] Clough R, Penzien J. Dynamics of structures. 2nd ed. New York: McGraw-Hill; 1993. p. 738.

[18] Faleiro J, Barbat AH, Oller S. Aplicação de Modelos de Dano e Plasticidade Concentrado para o Calculo Matricial de Estruturas de Concreto Armado. In: $47^{\circ}$ Congresso Brasileiro do Concreto, Refice - Brazil: IBRACON; 2005. ibracon1.locaweb.com.br.

[19] Argyris JH, Boni B, Kleiber M. Finite element analysis of two and three-dimensional elasto-plastic frames - the natural approach. Comput Methods Appl Mech Eng 1982;35:221-48.

[20] Simo JC, Hughes TJR. Computational inelasticity. Springer-Verlag; 1998.

[21] Flórez-López J. Plasticidad y Fractura en Estructuras Aporticadas, In: Barbat AH, editor. Monografías de Ingeniería Sísmica, CIMNE Centro Internacional de Metodos Numéricos en Ingeniería: Barcelona, 1999. p. 90.

[22] Faleiro J, Barbat AH, Oller S. Plasticidade e Dano em Pórticos de Concreto Armado. In: $46^{\circ}$ Congresso Brasileiro do Concreto. Florianóplis - Brazil: IBRACON; 2004. ibracon1.locaweb.com.br.

[23] Malvern L. Introduction to the mechanics of a continuos medium. Prentice-Hall; 1969.

[24] Oller S. Fractura mecánica - un enfoque global. Barcelona: CIMNE; 2001.

[25] Salamy MR, Kobayashi H, Unjoh S. Experimental and analytical study on RC deep beams. In: Second International Conference on Concrete \& Development, 2005.

[26] Lubliner J, Oliver J, Oller S, Onate E. A plastic-damage model for concrete. Int J Solid Struct 1989;25(3):299-326.

[27] Jirásek M, Bazant ZP. Inelastic analysis of structures. New York: John Wiley \& Sons; 2002.

[28] Álvares MS, Aplicação de um Modelo de Dano Localizado a Estruturas de Barras em Concreto Armado [pdf], 2004. Available from: www.ucg.br/nupenge/jornada.htm [cited 2004 jully 20].

[29] Car E, Oller S, Oñate E. An anisotropic elastoplastic constitutive model for large strain analysis of fiber reinforced composite material. Comput Methods Appl Mech Eng 2000;185(2-4):245-77.

[30] Barbat AH, Cervera M, Hanganu A, Cirauqui C, Oñate E. Failure pressure evaluation of the containment building of a large dry nuclear power plant. Nucl Eng Design 1998;180:251-70.

[31] Barbat AH, Canet JM. Estructuras Sometidas a Acciones Sísmicas, 2nd ed., vol. 1. Barcelona: CIMNE; 1994. p. 821. 